\title{
Mass Spectrometry in the U.S. Space Program: Past, Present, and Future
}

\author{
Peter T. Palmer \\ Department of Chemistry and Biochemistry, San Francisco State University, San Francisco, California, USA
}

Thomas F. Limero

Wyle Life Sciences Inc., Houston, Texas, USA

\begin{abstract}
Recent years have witnessed significant progress on the miniaturization of mass spectrometers for a variety of field applications. This article describes the development and application of mass spectrometry (MS) instrumentation to support of goals of the U.S. space program. Its main focus is on the two most common space-related applications of MS: studying the composition of planetary atmospheres and monitoring air quality on manned space missions. Both sets of applications present special requirements in terms of analytical performance (sensitivity, selectivity, speed, etc.), logistical considerations (space, weight, and power requirements), and deployment in perhaps the harshest of all possible environments (space). The MS instruments deployed on the Pioneer Venus and Mars Viking Lander missions are reviewed for the purposes of illustrating the unique features of the sample introduction systems, mass analyzers, and vacuum systems, and for presenting their specifications which are impressive even by today's standards. The various approaches for monitoring volatile organic compounds (VOCs) in cabin atmospheres are also reviewed. In the past, ground-based GC/MS instruments have been used to identify and quantify VOCs in archival samples collected during the Mercury, Apollo, Skylab, Space Shuttle, and Mir missions. Some of the data from the more recent missions are provided to illustrate the composition data obtained and to underscore the need for instrumentation to perform such monitoring in situ. Lastly, the development of two emerging technologies, Direct Sampling Ion Trap Mass Spectrometry (DSITMS) and GC/Ion Mobility Spectrometry (GC/IMS), will be discussed to illustrate their potential utility for future missions. (J Am Soc Mass Spectrom 2001, 12, 656-675) (C) 2001 American Society for Mass Spectrometry
\end{abstract}

I n the late 1980s and early 1990s, MS instrumentation underwent an evolution from complex, room-sized instruments to more user-friendly, bench-top equipment. These instruments were enthusiastically marketed and sold by a variety of instrument manufacturers. Recent research and engineering advances have led to further reductions in the size of mass spectrometers and resulted in the development of new ones based on novel approaches [1-3]. Although these miniaturized mass spectrometers have not been embraced by the major instrument manufacturers because of perceptions of limited markets and/or profit margins, the National Aeronautics and Space Administration (NASA) has supported their development because of its need for small, analytically powerful instruments to further its goals for the exploration of space.

Published online May 1, 2001

Address reprint requests to Dr. P. T. Palmer, Department of Chemistry and Biochemistry, San Francisco State University, San Francisco, CA 94132-4163. E-mail: palmer@sfsu.edu
A few review articles discuss the use of MS for space applications [4-7]. Many of the primary references on this topic are buried in NASA technical memoranda and/or technical papers presented at the International Conference on Environmental Systems (ICES). It should be noted that ICES papers are published by the Society for Automotive Engineering (SAE) in its technical paper series, and some selected papers are also available in SAE Transactions-Journal of Aerospace. As these references may be unknown and/or not readily available to most scientists, significant effort has been made to include detailed references to many of these documents.

MS instruments developed specifically for space applications or uniquely suited to these applications are based on nearly every type of mass analyzer. These include time-of-flight (TOF) [8,9], sector instruments [10-12], quadrupole arrays [13-16], quadrupole ion traps [17], and cylindrical ion trap mass spectrometers [18-20]. In addition to the two main space applications of MS, which are discussed in detail here, MS has also been used for other specialized space-related applica- 


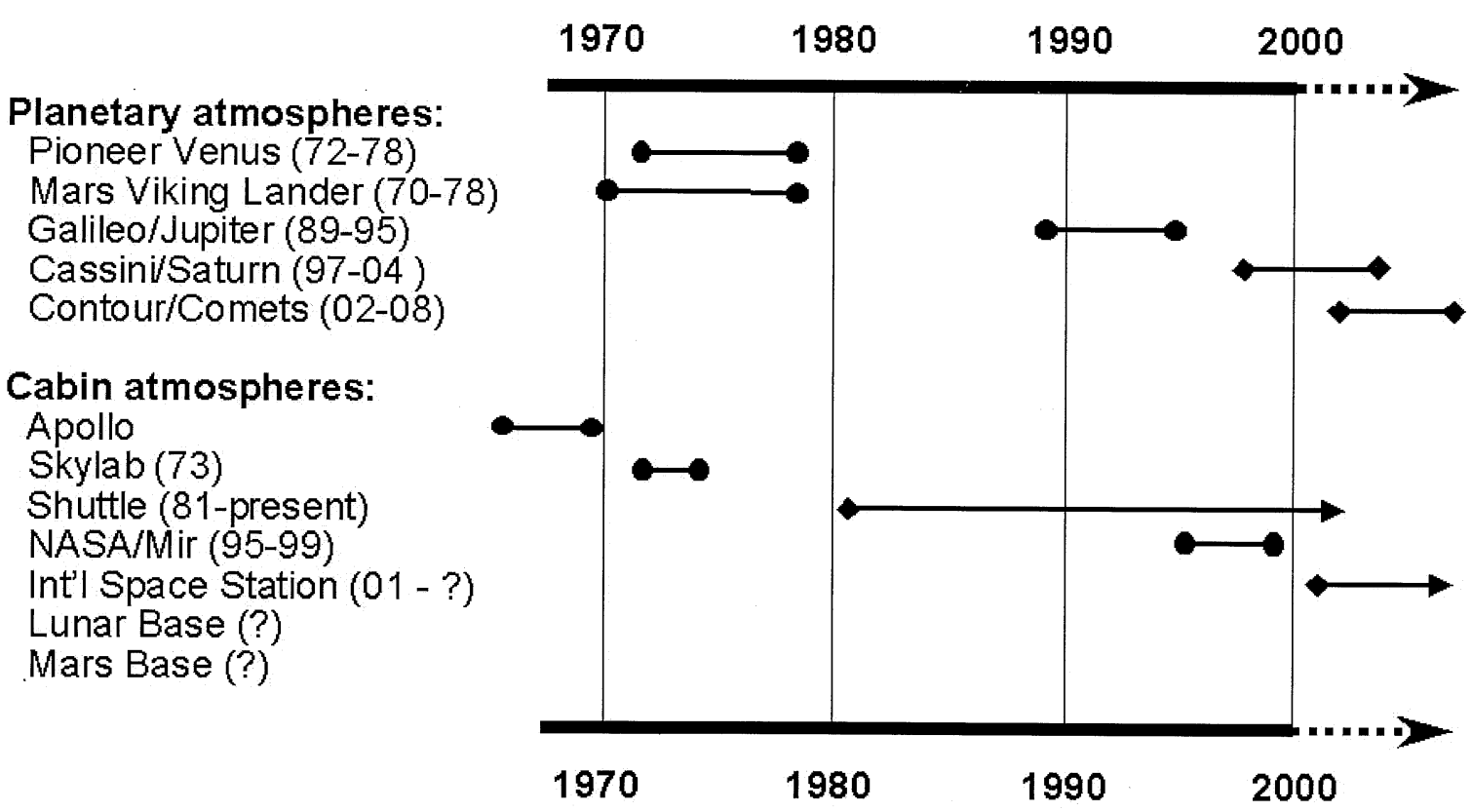

Figure 1. Timeline of the use of MS to support selected missions in the U.S. Space Program.

tions. These include the analysis of human breath to study the effects of microgravity on respiratory function [21-24], testing for propellant leaks prior to launches of the Space Shuttle [25-27], and validating the performance of trace contaminant removal in advanced life support systems [28]. Some of the aforementioned advanced MS concepts have been proposed for identifying sources of coolant or fuel leaks external to spacecraft during extravehicular activity (EVA) [29, 30]. These more specialized applications are not discussed further here.

The primary focus of this article is to present a cross section of the various MS instruments and methods that have been deployed and used on U.S. spacecraft, or have played a role in generating data from U.S. space missions. The main emphases are the application of MS to the analysis of gases in the atmospheres of planets in the solar system, and monitoring VOCs in cabin air samples from manned space missions. It reviews some early successes of mass spectrometers for the Venus Pioneer [4, 5, 31-33] and Mars Viking Lander [34-36] missions and details the use of archival sampling and subsequent ground-based GC/MS analyses of VOCs in cabin atmospheres on the Space Shuttle [37] and Mir Space Station missions [38, 39]. Finally, it will highlight the development of new technologies for monitoring cabin air quality on the International Space Station (ISS), and close with a discussion on future requirements and trends.

Space represents perhaps the most challenging environment for any instrument from the perspective of the necessity for operation under microgravity conditions and exposure to high $G$ forces, shock, and vibrations during takeoff and landing. Space deployment necessitates highly reliable operation, advanced automation, redundancy, and limited disposables. Instruments intended for planetary missions will be subjected to radiation, large variations in temperature and pressure, and the corrosive effects of molecular oxygen, radicals, and other species in upper atmospheres. For applications internal to a spacecraft, the instrument often must operate in a complex atmosphere of trace organic contaminants and high levels of water, carbon dioxide, hydrogen, and methane. Two "gates" in evaluating an MS instrument's suitability for space flight are practical considerations such as space, weight, and power requirements, and analytical performance criteria which include sensitivity, selectivity, precision and accuracy, speed and cycle times. In selecting and developing an instrument for a specific mission, NASA scientists must consider the appropriateness of the technology to support the scientific objectives of that mission, as well as the costs and the readiness of the technology to meet the strict and often inflexible constraints for that mission.

MS has been used with great success on planetary missions as space vacuum can be used to reduce resource demands, and the science objectives of such missions are well suited to MS. Many of the factors that reduce cost and enhance MS performance for planetary missions, work against this technology in the manned space program. Consequently, MS has been used sparingly in the manned program because of high cost, large resource demands, and suspected unreliability in the more complex spacecraft atmospheres. A timeline for MS applications in space is shown in Figure 1. Although this figure is not intended to be all-inclusive and some of the dates may not be exact, its intent is to use representative missions to illustrate the considerable time periods required for instrument inception, development, and deployment. The time, effort, and com- 
plexity of getting an instrument flight-qualified cannot be underemphasized. One interesting feature evident in this figure is the gap in activity during the 1980s. This can be attributed to the lack of any major planetary missions and/or NASA's focus on the Shuttle program during this time period.

\section{Monitoring Planetary Atmospheres}

The study of the composition of planetary atmospheres is of interest for several reasons. Actual data on compounds and their concentrations allow new insights into theories of planetary formation and models of planet evolution. Isotopic data provide valuable information on the evolution of the solar system. The presence of organic molecules in the soil may provide evidence of life on other planets. Although remotesensing-based spectroscopic methods can be used to infer atmospheric composition, MS provides the ability to definitively identify a variety of atmospheric constituents across a wide range of concentrations that can approach eight orders of magnitude [4]. In practice, both spectroscopic and mass spectrometric techniques have been used in a complementary manner to contribute to the understanding of planetary and atmospheric dynamics.

Potential target compounds in planetary atmospheres includes common gases, acids, and bases, as well as other gases and isotopes that are not normally found on Earth. Although MS can be employed to identify and quantify these species, the use of a mass analyzer with only unit mass resolution can complicate interpretation of data, especially when considering the presence of fragment and doubly charged ions. This is illustrated in Table 1, which shows a surprisingly large number of isobaric species.

Great care must be exercised in order to ensure a representative sample. The inlet system could potentially become contaminated with fuel emissions and contaminants from off-gassing of materials from the spacecraft. Atomic oxygen could combine on inlet surfaces to form molecular oxygen. Sodium and other alkali metals may be sputtered off metal surfaces. All these factors must be taken into consideration in designing the sample introduction system. In addition, this system must also accommodate wide ranges in pressures ranging from fractions of a torr in rarefied upper atmospheres to surprisingly high pressures such as the $100 \mathrm{~atm}$ found near the surface of Venus. It should also be noted that telemetry rates and the probe's decent rate limit the amount of data that can be collected.

Niemann and Kasprzak provided an excellent albeit dated review of MS instrumentation for the determination of atmospheric composition [4]. Mahaffy has written a more recent review of these instruments which includes a discussion of new instrumentation developed for studying planetary and cometary atmospheres [5]. This discussion will focus on instruments used on the Pioneer Venus and Mars Viking Lander missions for
Table 1. Potential isobaric species at unit masses in the analysis of planetary atmospheres.

\begin{tabular}{llcl}
\hline $\begin{array}{l}\text { Nominal } \\
\text { mass }\end{array}$ & $\begin{array}{c}\text { Possible ion } \\
\text { at this } \\
\text { isobaric mass }\end{array}$ & $\begin{array}{c}\text { Nominal } \\
\text { mass }\end{array}$ & \multicolumn{1}{c}{$\begin{array}{c}\text { Possible ion } \\
\text { at this } \\
\text { isobaric mass }\end{array}$} \\
\hline \hline 1 & $\mathrm{H}^{+}$ & 26 & $\mathrm{C}_{2} \mathrm{H}_{2}^{+}$ \\
2 & $\mathrm{H}_{2}^{+}, \mathrm{D}^{+}$ & 27 & $\mathrm{HCN}^{+}$ \\
3 & $\mathrm{HD}^{+},{ }^{3} \mathrm{He}^{+}$ & 28 & $\mathrm{~N}_{2}^{+}, \mathrm{CO}^{+}, \mathrm{C}_{2} \mathrm{H}_{4}^{+}$ \\
4 & $\mathrm{He}^{+}$ & 29 & ${ }^{13} \mathrm{CO}^{+}, \mathrm{C}^{17} \mathrm{O}^{+},{ }^{15} \mathrm{NN}^{+}$ \\
5 & & 30 & $\mathrm{NO}^{+}$ \\
6 & & 31 & \\
7 & $\mathrm{Li}^{+}$ & 32 & $\mathrm{O}_{2}^{+}, \mathrm{SO}_{2}^{++}$ \\
8 & & 33 & \\
9 & & 34 & $\mathrm{H}_{2} \mathrm{~S}^{+}, \mathrm{O}^{14} \mathrm{O}^{+}$ \\
10 & & 35 & \\
11 & & 36 & ${ }^{36} \mathrm{Ar}^{+}, \mathrm{HCl}^{+}$ \\
12 & $\mathrm{C}^{+}$ & 37 & \\
13 & ${ }^{13} \mathrm{C}^{+}$ & 38 & ${ }^{38} \mathrm{Ar}^{+},{ }^{37} \mathrm{HCl}^{+}$ \\
14 & $\mathrm{~N}^{+}, \mathrm{N}_{2}^{++}$ & 39 & $\mathrm{~K}^{+}$ \\
15 & & 40 & $\mathrm{Ar}^{+}, \mathrm{Ca}^{+}$ \\
16 & $\mathrm{O}^{+}, \mathrm{O}_{2}^{++}, \mathrm{CH}_{4}^{+}$ & 41 & $4 \mathrm{~K}^{+}$ \\
17 & $\mathrm{OH}^{+}, \mathrm{NH}_{3}^{+}$ & 42 & $\mathrm{Kr}^{++}$ \\
18 & $\mathrm{H}_{2} \mathrm{O}^{+}$ & 43 & \\
19 & $\mathrm{HDO}^{+}, \mathrm{F}^{+}$ & 44 & $\mathrm{CO}_{2}^{+}, \mathrm{N}_{2} \mathrm{O}^{+}$ \\
20 & $\mathrm{Ne}^{+}, \mathrm{HF}^{+}$ & 45 & ${ }^{13} \mathrm{CO}_{2}^{+},{ }^{13} \mathrm{C}^{17} \mathrm{OO}^{+}$ \\
21 & & 46 & $\mathrm{NO}_{2}^{+}, \mathrm{C}^{18} \mathrm{OO}^{+}$ \\
22 & $\mathrm{CO}_{2}^{++},{ }^{22} \mathrm{Ne}^{+}$ & 47 & \\
23 & $\mathrm{Na}^{+}$ & 48 & \\
24 & & 49 & $\mathrm{H}_{2} \mathrm{SO}_{4}^{++}$ \\
25 & & 50 & \\
& & &
\end{tabular}

the purposes of highlighting their novel design features and showing how the resulting data from these missions illustrate the utility of MS for studying planetary atmospheres. Although numerous mass spectrometers have been developed to measure both neutral gases and ions in the rarified atmospheres, the latter application is not discussed further here. Finally, it should be noted that although new instruments have been developed and deployed for exploring other planetary and cometary bodies in the solar system, the data from these missions will not become available for some time due to the long transit times required to reach their objectives.

\section{Pioneer Venus Probe}

The Pioneer mission comprised several probes and five mass spectrometers, two of which are described here for the analysis of the upper and lower Venusian atmosphere [4, 31-33]. A schematic of the mass spectrometer used to study the upper atmosphere (140 to $300 \mathrm{~km}$ ) is shown in Figure 2 [31]. It employed an electron ionization (EI) source and a hyperbolic quadrupole mass analyzer (it should be noted that hyperbolic quadrupoles were not available in commercial instruments until the 1980s and 1990s). The vacuum manifold was evacuated prior to launch and a static getter pump was used to maintain vacuum during the mission. The integrity of the sampling system was preserved by a breakoff hat (not shown in Figure 2) until orbital 


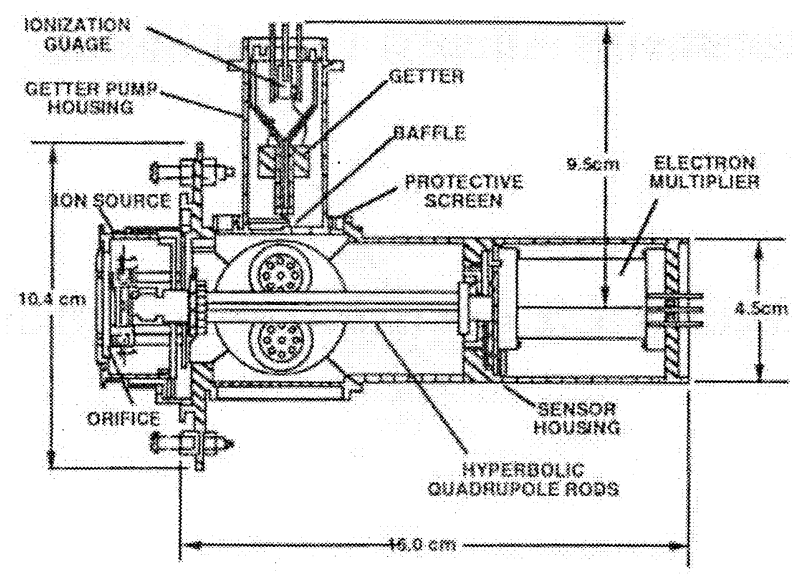

Figure 2. Schematic of mass spectrometer used to study the upper atmosphere on the Pioneer Venus mission [31].

insertion, at which time the hat was ejected to expose the inlet to the atmosphere. Several ingenious means were used to prevent potential misinterpretation of results. A voltage bias was applied to the inlet to prevent positive ions and electrons from the planetary atmosphere from entering the ion source. The velocity of atmospheric gases entering the inlet was exploited to differentiate between their signals and those from both background contamination in the instrument and metal ions sputtered off the instrument surfaces. The energy used for EI was decreased from 70 to $27 \mathrm{eV}$ to enable differentiation between $\mathrm{CO}_{2}^{++}$and ${ }^{22} \mathrm{Ne}^{+}$. A somewhat representative spectrum from a prototype version of this instrument is shown in Figure 3 [32]. This represents a mass spectrum of air sample in a ground-based experiment. The unusual peak shapes and deep valleys are due to the construction of the hyperbolic quadrupoles, which were designed to give less than $10^{-4}$ interference in ion intensity between adjacent peaks. On space missions, this performance is exploited along with peak stepping to enable faster data acquisition and telemetry rates than conventional scanning while preserving as much of the original peak shape as possible. The peaks due to $\mathrm{COS}, \mathrm{SO}_{2}$, and $\mathrm{Kr}$ are due to carryover from previous analyses of gas standards containing those species. It should be noted that the instrument flown to Venus re-entered the atmosphere in 1992 and was still functional-this after a time span of 14 years!

The Pioneer Venus probe included a second payload that was used to deliver another instrument to study the lower atmosphere (below $62 \mathrm{~km}$ ). A schematic of this instrument is shown in Figure 4 [33]. This instrument was controlled by the first microprocessor to ever fly in space. It used an EI source and a magnetic sector mass analyzer, and employed both getter and ion pumps to maintain vacuum. The proper operation of the vacuum system was critically important as the atmospheric pressure near the surface of Venus rises to hundreds of atmospheres. Sampling was accomplished through a tantalum-coated ceramic micro-leak (CML) valve that was protected from exposure to space by a break seal. The CML valve and sampling lines were fabricated from specially passivated tantalum steel to enable reliable measurement of sulfuric acid in the

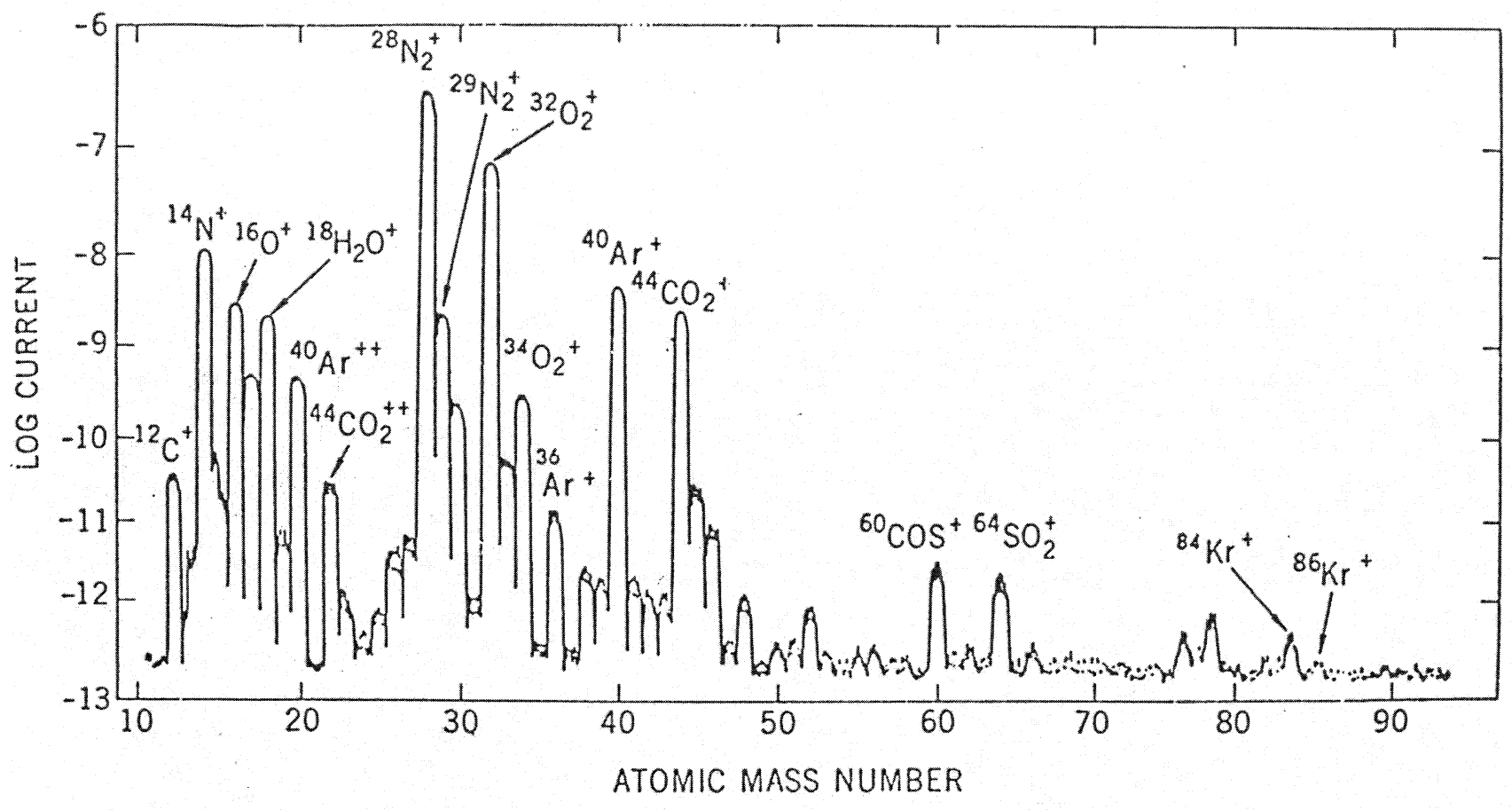

Figure 3. Mass spectrum of an air sample in a ground-based experiment illustrating the performance of prototype quadrupole mass spectrometer designed for planetary atmospheric analysis [32]. 


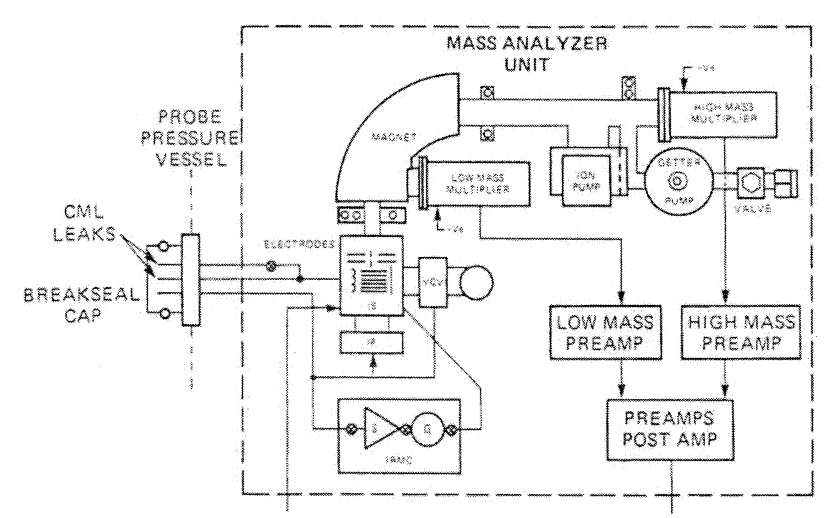

Figure 4. Schematic of mass spectrometer used to study the lower atmosphere on the Pioneer Venus mission [33].

Venusian atmosphere. A variable control valve (VCV) was continually adjusted using feedback from the ion pump to maintain constant pressure in the ion source and provide the wide dynamic range required to track ambient pressures ranging from 0.1 to $100 \mathrm{~atm}$ during the descent. Several adroit methods were exploited to discriminate between isobaric ions. A second inlet routed the sample through a getter pump to adsorb $\mathrm{H}_{2}$ and enable collection of additional data to discriminate between ${ }^{3} \mathrm{He}$ and HD. This instrument provided unanticipated results insofar as the Venusian atmosphere was found to contain $96 \% \mathrm{CO}_{2}$ and $4 \% \mathrm{~N}_{2}$, as well as more primordial argon (as indicated by a high ratio of ${ }^{36} \mathrm{Ar}$ to ${ }^{40} \mathrm{Ar}$ ) than found on Earth.

\section{Mars Viking Lander}

The Mars Viking Lander represents one of the more ambitious and perhaps the most well-known application of MS in space [34-36]. Its development included several major redesigns and input from numerous experts in MS and space sciences. This instrument was intended for both atmospheric and soil monitoring experiments, with the latter for the purpose of detecting organic chemicals which could potentially indicate the presence of other life in the universe. A schematic of the instrument is shown in Figure 5 [36]. It used an EI source and a double-focusing mass analyzer with the EB configuration (Nier-Johnson geometry). The atmospheric sampling inlet was similar to that described above for the instrument used to sample the upper Venusian atmosphere. The inlet system for the analysis of soil samples utilized $\sim 2-3 \mathrm{~mL}$ of ${ }^{13} \mathrm{CO}_{2}$ to serve as an internal standard and to purge thermally desorbed volatile compounds from one of three sample ovens onto a GC. The GC used $\mathrm{H}_{2}$ as a carrier gas to provide more efficient separations. GC flow to the MS was controlled by feedback from the ion pump to route effluent through one of five effluent dividers (with split ratios of $1,3,20,400$, and 8000 ) to extend the dynamic range of the MS detector. Two scrubbers were employed prior to mass spectrometric detection to con-

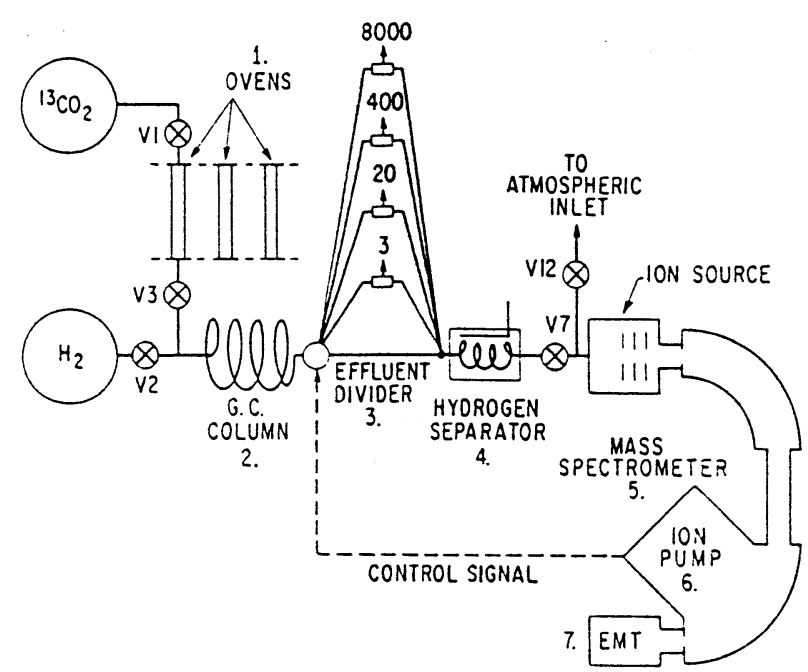

Figure 5. Schematic of mass spectrometer used on the Mars Viking Lander mission. Reproduced with permission [36]. Copyright (C) 1977 by the American Geophysical Union.

serve the ion pumps: an $\mathrm{Ag} / \mathrm{Pd} / \mathrm{NaOH}$ scrubber to remove $\mathrm{H}_{2}$ carrier gas and an $\mathrm{Ag}_{2} \mathrm{O} / \mathrm{LiOH}$ scrubber (not shown in Figure 5) to remove $\mathrm{CO}$ and $\mathrm{CO}_{2}$ and enable detection of $\mathrm{N}_{2}$. Although the data from this mission indicated the presence of methyl chloride and fluorocarbon oxides, these species were determined to be of terrestrial origin as they were detected in prior testing of the instrument on Earth. Although Martian surface and subsurface soil was tested at two locations and no organic compounds were detected, the instrument functioned as planned with the exception of one malfunctioning oven. A significant result from the Viking analyses was that Martian soil might be reactive [40]. The testing of this hypothesis will be one of the science objectives planned for a future mission to Mars. Until recently, the Mars Viking Lander mission represented the most remote application of MS.

\section{Future Missions and Emerging Technologies}

While the Pioneer Venus and Mars Viking Lander instruments were developed nearly 30 years ago, their specifications are amazing even by today's standards. Table 2 provides some comparison data for these instruments. It is somewhat surprising to note that few of today's miniature MS instruments have comparable size, weight, and power requirements. This may be due to the fact that more modern instruments intended for space applications must also include their own dedicated control computer(s). Moreover, as the science and technology associated with these instruments have matured, the instruments have become more complex and more versatility is demanded from them.

Mass spectrometers continue to be deployed for the analysis of the atmospheres of Saturn's largest moon Titan, Jupiter, and several comets. Three more recent instruments that deserve mention include the Galileo 
Table 2. Comparison of selected specifications of mass spectrometers used for monitoring planetary atmospheres.

\begin{tabular}{lccl}
\hline Instrument & $\begin{array}{c}\text { Pioneer Venus- } \\
\text { Upper Atmosphere }\end{array}$ & $\begin{array}{c}\text { Pioneer Venus- } \\
\text { Lower Atmosphere }\end{array}$ & $\begin{array}{c}\text { Mars Viking } \\
\text { Lander }\end{array}$ \\
\hline \hline Mass Analyzer & quadrupole & magnetic sector & dual sector (B/E) \\
Detection Limit & N/A & $1 \mathrm{ppmv}$ & ppbv-ppmv (soil) \\
Mass Range & $1-46 \mathrm{Th}$ & $1-208 \mathrm{Th}$ & $12-250 \mathrm{Th}$ \\
Size & $\mathrm{N} / \mathrm{A}$ & $\mathrm{N} / \mathrm{A}$ & $0.6 \mathrm{ft}^{3}$ \\
Weight & $8.4 \mathrm{lbs}$ & $24 \mathrm{lbs}$ & $45 \mathrm{lbs}^{-}$ \\
Power & $12 \mathrm{~W}$ & $14 \mathrm{~W}$ & 140 \\
\hline
\end{tabular}

Probe mass spectrometer, the Cassini Orbiter ion/ neutral mass spectrometer, and the Huygens Probe mass spectrometer. The neutral mass spectrometer on the Galileo Probe provided significant information on the composition of the Jovian atmosphere [41]. The Cassini-Huygens Probe, with its five different ion sources and quadrupole mass spectrometer, will reach the moon Titan in the Saturn system in 2004 [42]. In addition, several other instruments are in various stages of planning, development, or deployment for a number of comet probe missions. The instruments developed for these missions have evolved from the same basic configurations described above, although in some cases major redesigns were required because of the lack of old parts. Although this work is certainly much more recent than either the Venus and Mars Viking Lander missions, little published information on these instruments is available at this time, and hence further discussion is deferred to some future date when the data from these missions becomes available.

Future needs for these types of missions include higher mass resolution to minimize isobaric interferences, in situ standards to enable measurement of very low concentrations of rare isotopes, and sample introduction systems capable of analyzing particulates and aerosols. Additionally, better instrumentation to characterize planetary surfaces is needed. Towards this end it should be noted that a laser-based ionization source was recently coupled to a TOF instrument for the analyses of both inorganic and organic species in planetary surfaces [43-45].

\section{Monitoring Cabin Air Quality}

Spacecraft are semi-closed environments that rely on various means of air revitalization to clean and recirculate the air [46, 47]. All manned spacecraft include an Environmental Control and Life Support System (ECLSS) which is designed to maintain a safe balance between the generation and accumulation of air contaminants in nominal conditions. The primary sources of contamination in cabin atmospheres are shown in Figure 6. Air quality may be compromised by human metabolites, contaminants that have escaped from containment (fuels, coolants, and ongoing experiments), outgassing from materials, and thermal degradation byproducts. Some studies have even shown a rise in contaminant concentrations after docking of resupply vehicles [48], indicating that a spacecraft is not a completely closed environment.

The scope of cabin air quality monitoring must include permanent gases important to respiratory function, analysis of trace levels of VOCs known or expected to be present in space environments, and unexpected or heretofore unknown contaminants. Before 1990, realtime air quality monitoring on U.S. spacecraft had been limited to a few major atmospheric components such as oxygen, carbon dioxide, and water vapor, measured as dew point [49]. The earliest use of MS for monitoring VOCs in the cabin atmospheres dates back to the Skylab missions [50]. NASA placed greater emphasis on periodic monitoring of VOCs beginning with the Apollo and Space Shuttle missions [37]. This has been achieved by collecting archival air samples, which are returned to Earth for subsequent analysis by GC/MS.

When selecting archival samplers for flight, consideration must be given to minimizing size, weight, power, complexity, and crew time required for sample collection. The two most common sample collection devices used for this purpose are referred to by NASA as the Grab Sample Container (GSC) and the Solid Sorbent Air Sampler (SSAS). Both of these sampling devices are depicted in Figure 7. The GSC is a $350-\mathrm{mL}$ Summa-treated canister and is used to collect instantaneous or grab samples. The SSAS is comprised of eight individual sampling tubes, each containing multiple sorbents for collecting VOCs. These devices have been used for collecting archival air samples on both Space Shuttle and NASA/Mir missions. During a mission, the SSAS's internal sampling pump is typically used to pull cabin air through a tube at a low flowrate for 24 hours. The SSAS must be manually activated and an astronaut must record the sampling time. The sample volume is determined from both the sampling time and the sampling flowrate, which is calibrated on the ground prior to and after each mission). The SSAS can be used to collect up to seven time-averaged samples (the eighth position on the SSAS device is used as a park position when no sample is being collected). Once returned to Earth, each SSAS tube is desorbed into a $500-\mathrm{mL}$ Summa-treated canister. Although this is a somewhat unconventional technique for the analysis of VOCs on sorbent traps, it permits replicate analyses of individual samples and has proven to be a reliable means for 


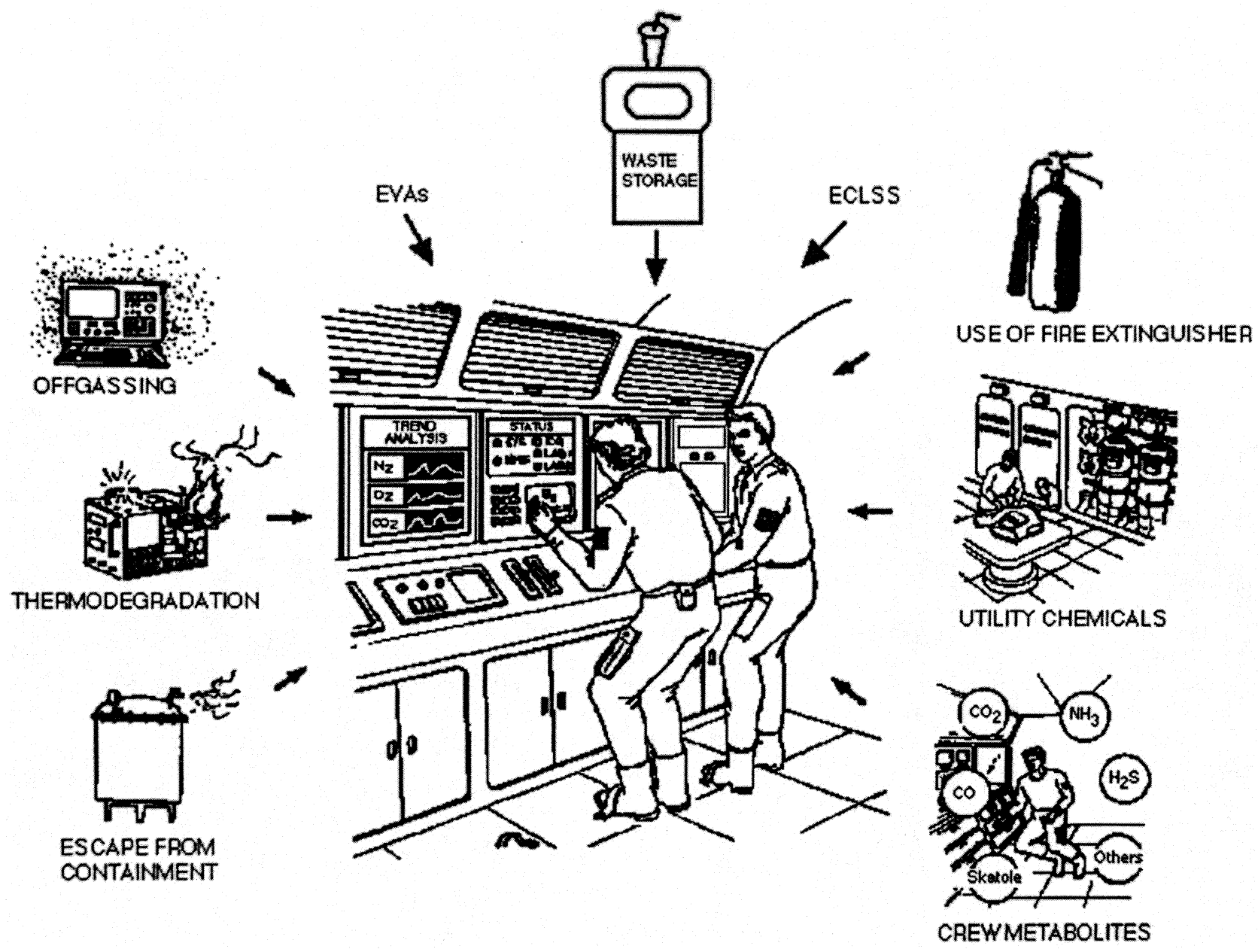

Figure 6. Sources of various air contaminants in the semi-closed environment of a cabin atmosphere on a space mission.

desorbing VOCs off of the SSAS and into a separate sample container. The GSC and SSAS are complementary sampling devices: the canisters are appropriate for sampling species that are not retained on a sorbent bed (permanent gases, very volatile freons, etc.) and for grab and/or contingency sampling, whereas the SSAS is used to provide time-averaged composition data.

Typical analyses of GSC and SSAS samples involves the use of several methods, as no single analytical method is capable of measuring the wide variety of permanent gases, VOCs, and other target compounds that are present in a cabin atmosphere. Initial analyses are performed on a GC equipped with conventional detector(s) to quantify permanent gases and low molecular weight species. Subsequent analyses utilize GC/MS to determine VOCs. A photograph of the current analytical system used in the Toxicology Laboratory at NASA Johnson Space Center (JSC) to perform these analyses is shown in Figure 8. The current system utilizes an Entech automated air concentrator, Hewlett-Packard model 6890 GC (Palo Alto, CA), and a Hewlett-Packard model 5973 MS instrument. The protocol used for VOC analyses is similar to the U.S. Environmental Protection Agency's (EPA) TO-14 method, but has been modified to enable the analysis of numerous polar compounds known to be present in cabin atmospheres. A listing of target compounds monitored via GC/MS by the JSC Toxicology Lab is shown in Table 3. It should be noted that this list and hence the analytical protocols require continual modifications to identify and quantify the contaminants specific to particular missions and situations, as the air composition and target compounds change depending on the environment and payloads.

One of the primary purposes of collecting archival samples is to enable a toxicological assessment of the spacecraft air quality during a mission. This is achieved by comparing the concentrations obtained from ground-based analyses of these samples to established values referred to as Spacecraft Maximum Allowable Concentrations (SMACs). NASA has established SMACs for durations ranging from one hour to six months. The typical range of concentrations for selected compounds, their method detection limits, and 30-day SMAC values are shown in Table 4. Further details on the development of SMACs, toxicological assessment of 


\section{GRAB SAMPLE CONTAINER (GSC): $0.35 \mathrm{~L}$ stainless steel canisters passivated surfaces instantaneous "whole air" samples used for VOC analysis, especially permanent gases not collected on sorbent trap}

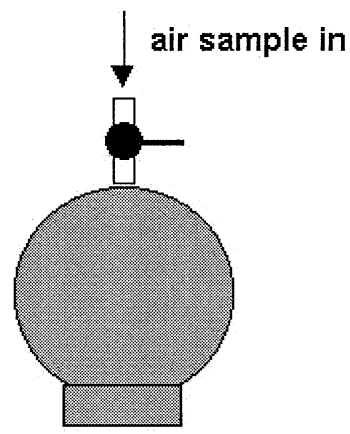

\section{SOLID SORBENT AIR SAMPLER (SSAS): 8 cartridges packed with sorbent agent(s) battery powered sampling pump low flow rates $(\sim 1 \mathrm{~mL} / \mathrm{min})$ 24-hour time-averaged samples used for VOC analysis}

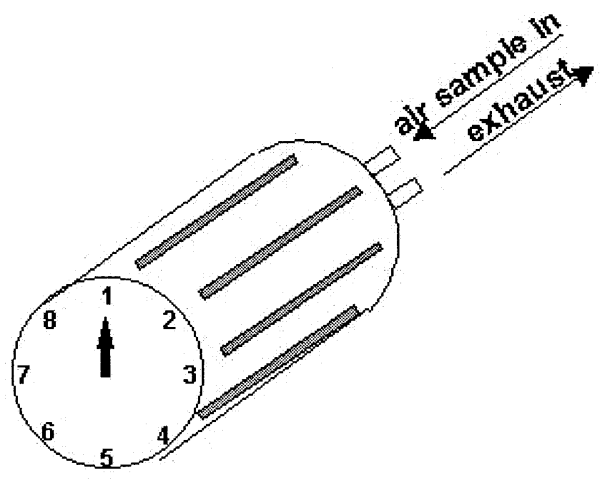

Figure 7. Depiction of GSC and SSAS devices used for sampling cabin atmospheres.

composition data from various missions are provided elsewhere [51-53].

\section{Space Shuttle}

Early in the development of the Shuttle, a GC/MS instrument based on the Mars Viking Lander technology was proposed for in situ measurement of VOCs. The electronics, control computer, and the instrument's use of preconcentration, valves, and numerous heated zones resulted in a device that weighed $135 \mathrm{lbs}$ and consumed $150 \mathrm{~W}$. This instrument was never deployed as "funding shortfalls and the management perception that such an instrument was not essential on (Shuttle's) Spacelab resulted in (its) cancellation at the breadboard stage" [7]. Consequently, analyses of cabin atmospheres required collection of archival air samples from the cabin for subsequent analysis on Earth.

Early in the Shuttle program, the SSAS was developed at JSC and manifested along with the GSCs for cabin air sample collection. Sensor technology limitations, relatively short missions, and spacecraft resource constraints continued to restrict the use of real-time monitors in the Shuttle program until 1990. A series of Shuttle incidents that degraded the cabin air quality [54] led NASA to develop the Combustion Products Analyzer (CPA) - the first portable, real-time air monitor to routinely fly on Shuttle missions. This handheld device, containing several electrochemical sensors, was de- signed to detect compounds such as $\mathrm{CO}$ and $\mathrm{HCl}$ following a fire. Obviously, MS was never a candidate for this analytical task. Nevertheless, GC/MS analyses of archival samplers provided valuable data on the dynamics of contaminants in spacecraft atmospheres through the Shuttle era. The utility of such data is illustrated in Figure 9, which plots trends in the concentration of selected contaminants versus time [37]. The decreasing trends (Figure 9A) indicate that these particular contaminants were removed by the air recirculation system. The increasing trends (Figure 9B) show that other contaminants were not removed as effectively and were indeed accumulating in the air onboard the Shuttle. Such information is of great interest to NASA in evaluating the performance of ECLSS and improved trace contaminant control subsystems.

\section{Mir Space Station}

The NASA/Mir program focused on the development and testing of new technologies to facilitate the transition to the space station era with its concomitant increase in mission length, more complex spacecraft systems, and greater number of sophisticated payload experiments. The rationale behind routine monitoring of cabin air quality on Mir included the need to provide data on a mature space station environment, ensuring the health of astronauts on long duration missions, and 


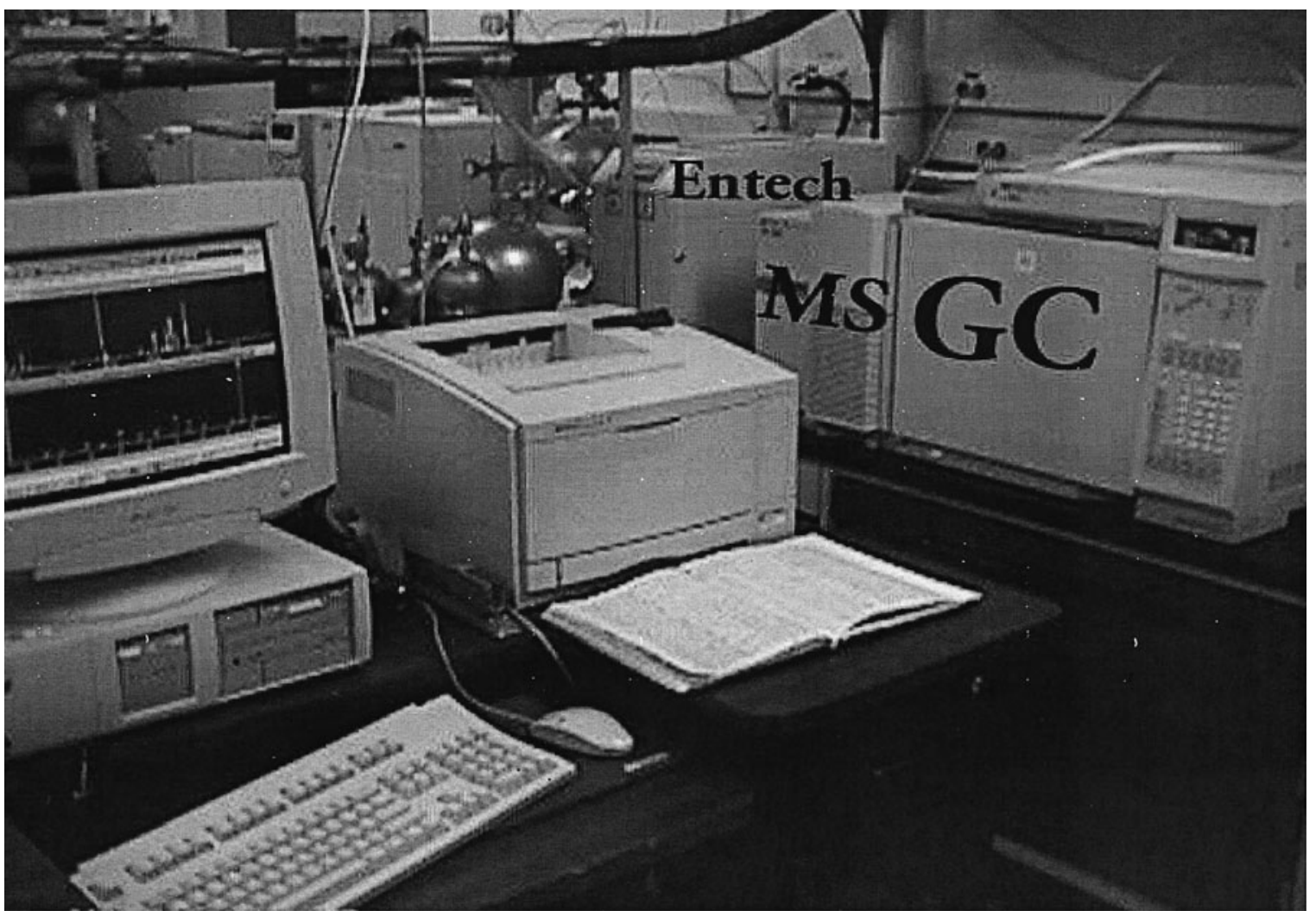

Figure 8. Photograph of analytical system used for ground-based GC/MS analyses of VOCs in archival samples of cabin atmospheres.

providing samples for testing new air quality monitoring technologies that might find application on the ISS. Archival samples were collected, returned to Earth, and analyzed by GC/MS and DSITMS.
Severe air quality degradations caused by leaks and thermal degradations on Mir served to highlight the need for real-time data [53]. In response to heat-exchanger fluid leaks and a major fire, NASA delivered

Table 3. Target compounds for the ground-based analysis of cabin atmospheres, including typical TO-14 and additional polar compounds known to be present, listed in approximate order of elution times on a DB-5 column.

\begin{tabular}{|c|c|c|}
\hline DICHLORODIFLUOROMETHANE & N-PROPANOL & TRANS-1,3-DICHLOROPROPENE \\
\hline CHLOROMETHANE & 1,1-DICHLOROETHANE & 1,1,2-TRICHLOROETHANE \\
\hline 1,2-DICHLORO-1,1,2,2-TETRAFLUOROETHANE & BUTANAL & TOLUENE \\
\hline ACETALDEHYDE & 2-BUTANONE & HEXANAL \\
\hline METHANOL & 1,2-DICHLOROETHENE & MESITYL OXIDE \\
\hline VINYL CHLORIDE & 2-METHYLFURAN & 1,2-DIBROMOETHANE \\
\hline BROMOMETHANE & ETHYL ACETATE & BUTYL ACETATE \\
\hline ETHANOL & HEXANE & TETRACHLOROETHENE \\
\hline CHLOROETHANE & CHLOROFORM & CHLOROBENZENE \\
\hline ACETONITRILE & 2-BUTENAL & ETHYLBENZENE \\
\hline PROPENAL & 1,2-DICHLOROETHANE & $\mathrm{M}-+\mathrm{P}-\mathrm{XYLENES}$ \\
\hline ACETONE & 1,1,1-TRICHLOROETHANE & 2-HEPTANONE \\
\hline PROPANAL & N-BUTANOL & CYCLOHEXANONE \\
\hline ISOPROPANOL & BENZENE & HEPTANAL \\
\hline TRICHLOROFLUOROMETHANE & CARBON TETRACHLORIDE & STYRENE \\
\hline FURAN & 2-PENTANONE & 1,1,2,2-TETRACHLOROETHANE \\
\hline ACRYLONITRILE & PENTANAL & O-XYLENE \\
\hline PENTANE & 1,2-DICHLOROPROPANE & 1,3,5-TRIMETHYLBENZENE \\
\hline 2-METHYL-2-PROPANOL & 1,4-DIOXANE & 1,2,4-TRIMETHYLBENZENE \\
\hline METHYL ACETATE & TRICHLOROETHENE & 1,3-DICHLOROBENZENE \\
\hline 1,1-DICHLOROETHENE & 2,5-DIMETHYLFURAN & 1,4-DICHLOROBENZENE \\
\hline DICHLOROMETHANE & 4-METHYL-2-PENTANONE & 1,2-DICHLOROBENZENE \\
\hline 3-CHLOROPROPENE & CIS-1,3-DICHLOROPROPENE & 1,2,4-TRICHLOROBENZENE \\
\hline 1,1,2-TRICHLORO-1,1,2-TRIFLUOROETHANE & 2-PENTENAL & HEXACHLORO-1,3-BUTADIENE \\
\hline
\end{tabular}


Table 4. Range of concentrations, method detection limits, and SMACs for selected permanent gases and VOCs monitored on the Space Shuttle.

\begin{tabular}{lccr}
\hline Compound & $\begin{array}{c}\text { Mean Concentration } \\
\text { Range }\left(\mathrm{mg} / \mathrm{m}^{3}\right)\end{array}$ & $\begin{array}{c}\text { Method Detection } \\
\text { Limit }\left(\mathrm{mg} / \mathrm{m}^{3}\right)\end{array}$ & $\begin{array}{r}\text { SMAC } \\
\left(\mathrm{mg} / \mathrm{m}^{3}\right)\end{array}$ \\
\hline \hline Hydrogen & Trace $-<3.3$ & 0.41 & 340 \\
Methane & Trace -29.0 & 6.6 & 3800 \\
Methanol & Trace -0.42 & 0.05 & 9 \\
Ethanol & Trace -2.6 & 0.05 & 2000 \\
Acetone & Trace -0.20 & 0.05 & 50 \\
i-Propanol & Trace -2.0 & 0.05 & 150 \\
Dichloromethane & Trace -0.10 & 0.05 & 50 \\
Freon 113 & Trace -0.06 & 0.05 & 400 \\
n-Butanol & Trace -0.25 & 0.05 & 80 \\
Toluene & Trace -0.18 & 0.05 & 60 \\
\hline
\end{tabular}

ethylene glycol Drager tubes and the CPA, respectively, to Mir. The Solid Fuel Oxygen Generator (SFOG) fire on Mir truly illustrated the need for in situ analysis to validate the efficient operation of the trace contaminant removal system and to provide astronauts with timely information on potentially hazardous situations resulting from poor air quality. Samples were collected before and after the SFOG event, and some of the results from GC/MS analyses of these samples are presented in Figure 10. Although the fire's release of CO represented perhaps the biggest threat to the crew, it also generated emissions of aromatic hydrocarbons (benzene and styrene), oxygenated hydrocarbons (i-propanol), and nitrile compounds (2-methyl-2-propene-nitrile). With the exception of $\mathrm{CO}$, benzene was of the most concern from a toxicological standpoint, although the highest concentration of benzene measured was still an order of magnitude below the 24-hour SMAC limit of $10 \mathrm{mg} / \mathrm{m}^{3}$ [52]. The trend data from archival samples confirmed that the trace contaminant removal subsystem returned contaminant concentrations to pre-fire levels approximately 24 hours after the event. This event underscored and reinforced the need for a real-time VOC monitor to provide data to the decision-makers and psychological comfort to the crew on air quality. It is obvious that it takes time to clean the air following a severe event and composition data are needed during this time to direct actions on the ground and in the spacecraft.

In addition to routine GC/MS analyses on Mir samples, DSITMS analyses were also performed on samples from several Mir missions as part of a technology development study. SSAS samples that had been returned to JSC were desorbed into a canister, analyzed via GC/MS, and then repressurized for subsequent analysis via DSITMS methods at San Francisco State University. GSC samples were analyzed via GC/MS and repressurized for subsequent DSITMS analysis. The instrumentation and methods employed in these analyses are described elsewhere [38, 55-57]. The most promising features of DSITMS compared to GC/MS are the much faster response times, which are on the order of seconds, and the less complicated hardware, which requires neither an air concentrator nor a gas chromatograph. A potential drawback is the lack of selectivity, which is somewhat ameliorated by the use of MS/MS to provide selective detection of trace contaminants in complex air samples.

From an analytical standpoint, one of the main issues
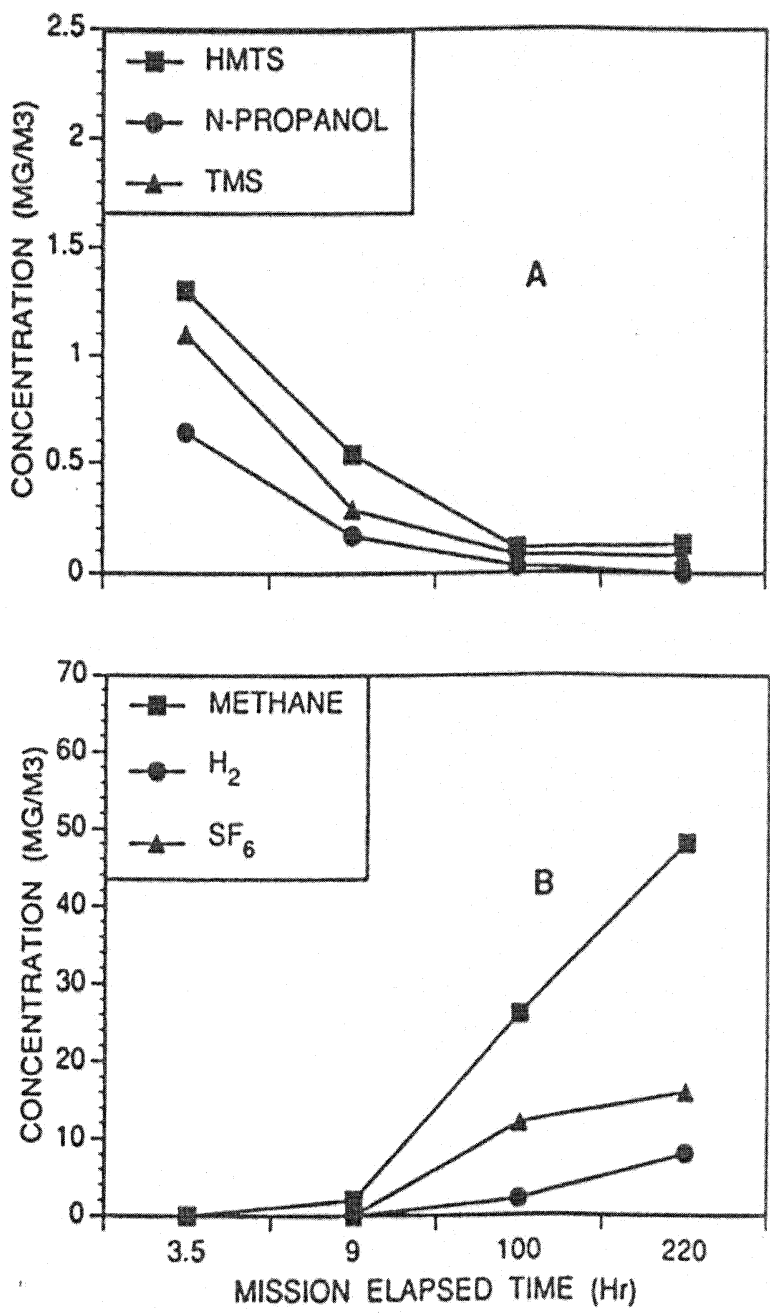

Figure 9. Trend data on selected contaminants from analyses of air quality of Shuttle missions. Plot A shows trends for hexamethylcyclotrisiloxane (HMTS), n-propanol, and trimethylsilane (TMS). Plot B shows trends for methane, hydrogen, and sulfur hexafluoride. Reproduced with permission [37]. 


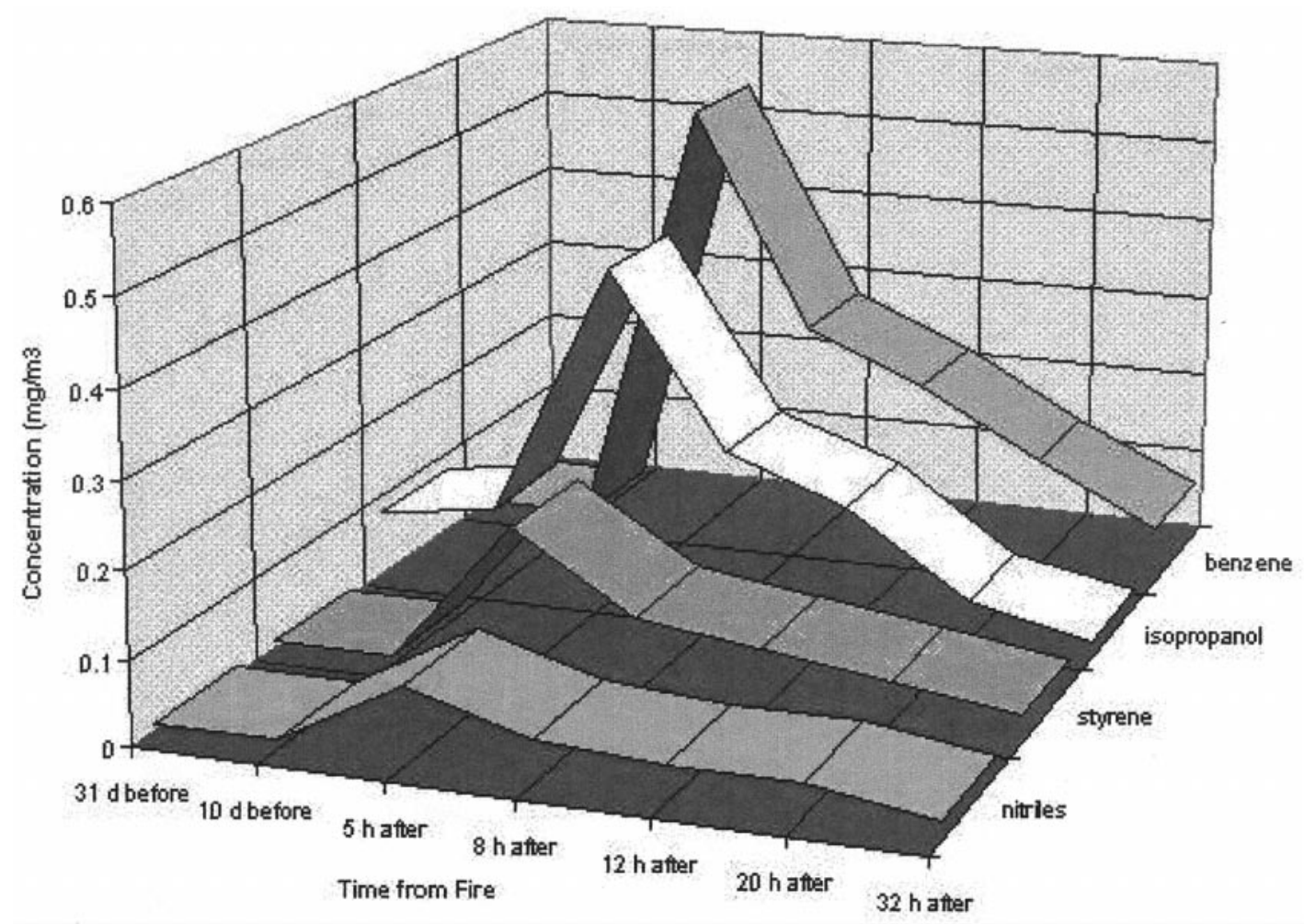

Figure 10. Trend data on several combustion products from the Mir fire event, showing the concentration of benzene, i-propanol, styrene, and nitriles before and after the SFOG fire (note time axis not to scale).

addressed in this work was proving that the DSITMS methods had requisite sensitivity to detect the various target compounds at or below their SMAC values. Benzene, one of the more toxic contaminants, has one of the lowest SMAC levels at 70 ppbv [52] for a 6-month time period. Figure 11 provides data showing that the instrument is capable of detecting $10 \mathrm{ppbv}$ levels of several VOCs in full scan mode. Although the detection limits of this technique in MS, SIM, and MS/MS modes are lower than the specified SMAC values, only a few VOCs were detected via DSITMS in the actual Mir samples. This was due to a combination of length of time between sample collection and analysis, and the repressurizations at JSC that diluted the already low concentrations of the VOCs on Mir.

In performing DSITMS analyses on the Mir samples, MS/MS mode was desired to enable selective detection of VOCs, but the limited volumes of samples available, $(\sim 100 \mathrm{~mL})$, led to the use of MS mode in order to provide the most information on a broad spectrum of VOCs. Figure 12 shows data from a Mir sample, with signals at $m / z 69,100,119,131$, and 181 indicating the presence of fluorocarbons, and signals at $m / z 78,91$, and 106 indicate the presence of aromatic hydrocarbons. Associated GC/MS analyses on the same samples confirmed the presence of perfluoropropane and perfluoro1,3-dimethyl-cyclohexane, which were the highest concentration VOCs found on Mir. Although MS/MS analyses could potentially confirm the presence and provide more reliable estimates of their concentrations, this would have required the use of $\mathrm{CI}$ techniques to concentrate the signal from a VOC into predominantly one ion, and greater sample volumes than were available for these studies. GC/MS analyses confirmed that the levels of the aromatic species in the sample were below DSITMS detection limits, and hence it is possible that these signals are due to background contamination. Additional analyses of other Mir samples showed the presence of sulfur hexafluoride in several samples as indicated by an intense signal at $\mathrm{m} / \mathrm{z} 127$. These results indicate the potential advantage of a single DSITMS technique to detect a range of compounds that would either not be detected by conventional GC/MS techniques (which are designed for organic compounds and not permanent gases), or would require the use of an additional GC analysis using an alternate stationary phase.

DSITMS offers several advantages over GC/MS methods. It uses neither sample preconcentration nor chromatography, and hence is simpler in its implementation and can provide much faster response times. DSITMS results have shown that the technique is capable of detecting most of the contaminants at levels that are typically several orders of magnitude below their SMAC values. However, the ion trap cannot definitively identify certain target compounds such as hydrogen, ethylene, formaldehyde, and the xylene isomers, as these species fall below the detectable mass range of the 


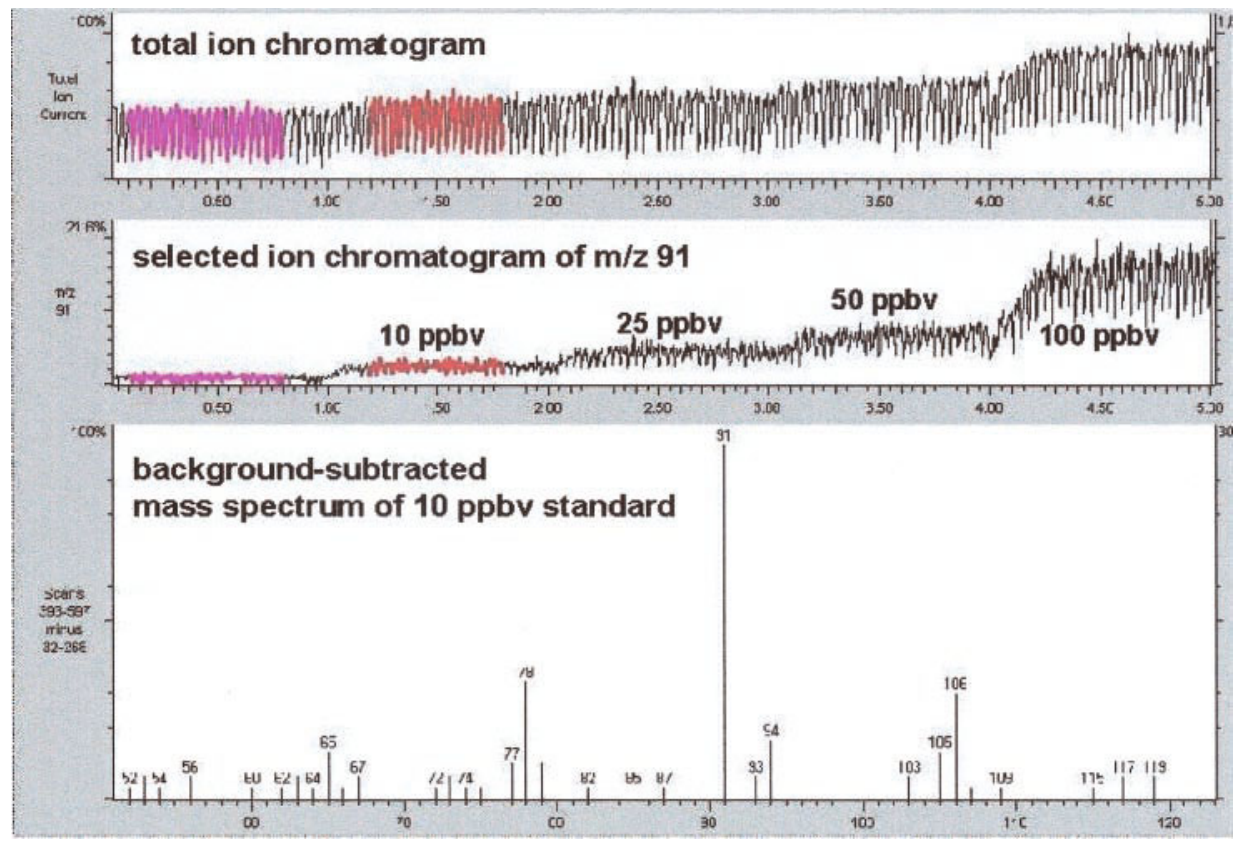

Figure 11. Results from DSITMS analyses of gas standards containing 10, 25, 50, and $100 \mathrm{ppbv}$ benzene, toluene, and xylene gas standards. The top two plots show a total ion chromatogram and a selected ion chromatogram of $\mathrm{m} / \mathrm{z}$ 91. The bottom plot is a background subtracted mass spectrum of the $10 \mathrm{ppbv}$ standard, showing detection of the quantitation ions for all three compounds.

instrument, have quantitation ions that overlap major constituents such as nitrogen, or cannot be differentiated by MS/MS. Although a commercial instrument manufacturer developed a prototype version of a fieldportable DSITMS instrument, it has since abandoned these efforts. Another manufacturer is nearing completion of its development of a DSITMS instrument to detect chemical and biological weapons defense applications. It should be noted that the DSITMS approach does not require the use of $\mathrm{He}$ as a buffer gas [55, 58], and hence a helium supply is not needed for this remote application of MS. Nevertheless, significant advances in pumping technology and miniaturization of DSITMS instruments are required to make this technology a

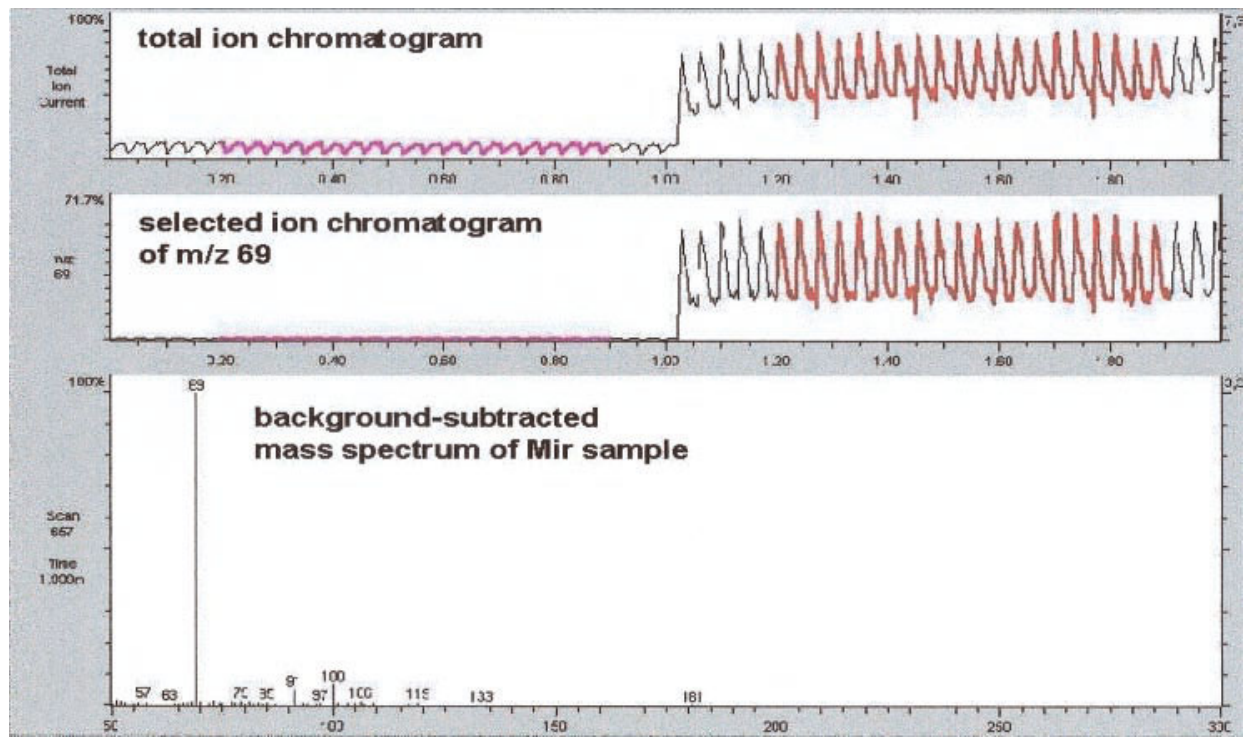

Figure 12. Results from DSITMS analyses of an archival, diluted sample from Mir. The top two plots show a total ion chromatogram and a selected ion chromatogram of $m / z 69$. The bottom plot shows a background subtracted mass spectrum of the sample, indicating the likely presence of perfluoropropane (as indicated by ions at $\mathrm{m} / \mathrm{z} 69$ and 119) and perfluorodimethylcyclohexane (as indicated by ions at $m / z 69,100,131$, and 181). Toluene, ethylbenzene, and/or xylenes may also be present (as indicated by ions at $m / z 91,92$, and 106). 


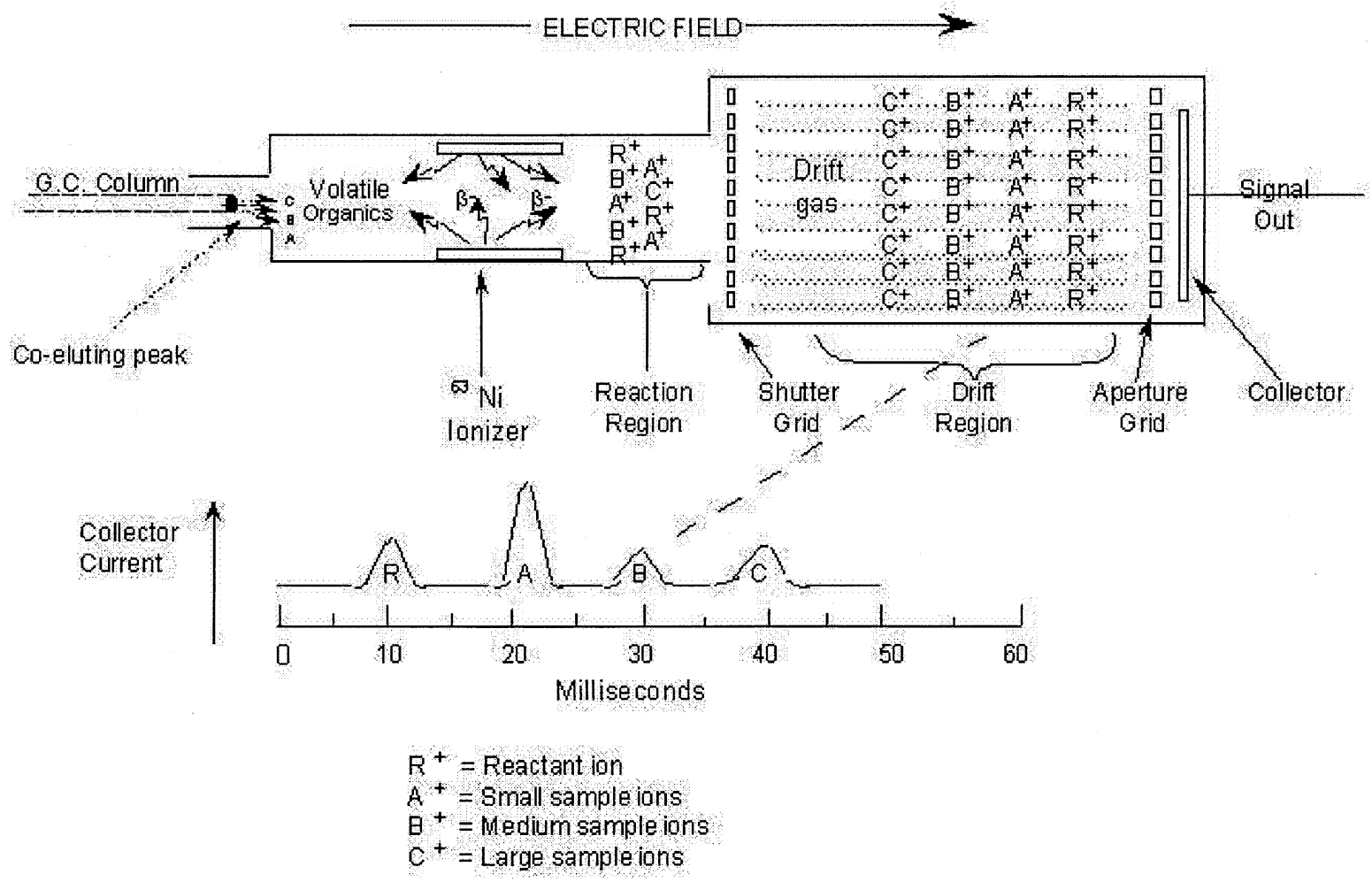

Figure 13. Schematic of GC/IMS technique, showing a ${ }^{63} \mathrm{Ni}$ ionizer where the GC effluent is ionized, a reaction region where charge exchange takes place, a drift region where the ions are separated, and a collector where the ions are detected. The resulting ion mobility spectrum represents a plot of collector current as a function of drift time.

viable option for in-situ monitoring of cabin atmospheres. Lastly, advanced automation of such instrumentation is essential if it is to be operated in remote environments, alleviate the astronauts from the details and complexities of the chemical analyses, and to provide the composition data in an easy-to-understand format.

\section{International Space Station}

After years of effort and several major redesigns, the first components of ISS were launched into Earth orbit in early 1999. Given the interest of maintaining longterm human presence in space, one of the most important reasons for monitoring cabin air quality is to ensure that the air is safe for the astronauts to breathe. Initially, instruments being considered for ISS were evaluated against a list of more than 200 compounds derived from analyses of contaminants from materials offgassing tests and from samples collected during manned missions [59]. Although many technologies are capable of measuring trace organic compounds, GC coupled with MS was and still is recognized as one of the more powerful techniques for this application due to its sensitivity and ability to positively identify a wide variety of VOCs from both retention time and mass spectral data. The list of target compounds for ISS is divided into permanent gases (i.e., oxygen, nitrogen, carbon dioxide, etc.) and VOCs (i.e., methanol, xylenes, benzene, etc.), as it was recognized that separate instruments would be required for each class. However, even GC/MS could not accurately identify and quantify all the VOCs on NASA's list. Data collected from archival samples during the Shuttle and NASA/Mir programs have been invaluable in identifying the significant compounds found in cabin atmospheres. Additional information from NASA toxicologists that considered the frequency of a compound's presence on the spacecraft, its potential concentration, and its toxicity, enabled the list of potential target VOCs to be reduced to the much more manageable number of approximately $30 \mathrm{com}$ pounds.

In addition to GC/MS, numerous technologies have been considered for monitoring cabin air quality. These include electrochemical sensors, electronic noses, array detectors, diode laser monitors, Fourier Transform Infrared Spectroscopy (FTIR), and mass spectrometry. MS still is the principle technology deployed in space for measuring permanent gases and human metabolic functions on manned space missions [21-24, 59, 60]. The ISS uses a version of the Viking mass spectrometer referred to as the Major Constituent Analyzer (MCA) to measure atmosphere components such as oxygen, carbon dioxide, and methane [61]. The technology under 

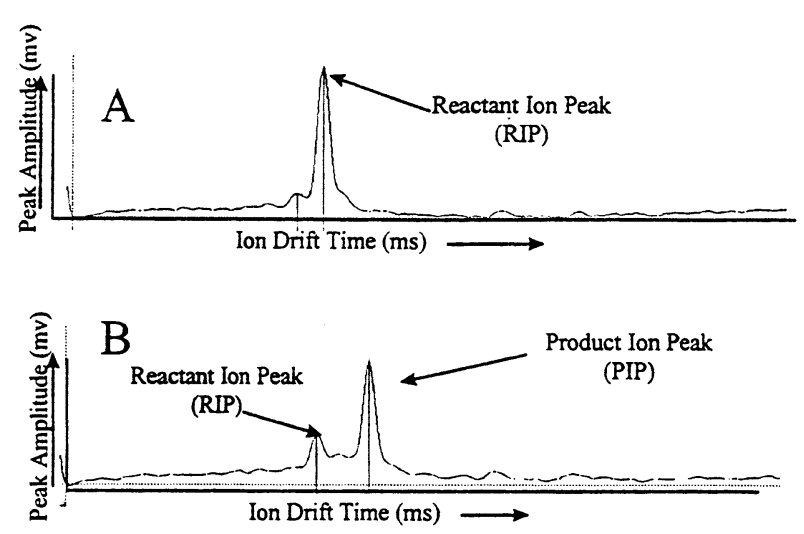

Figure 14. Ion mobility spectra plotting collector current as a function of drift time. Plot A represents a background spectrum of the GC effluent, showing a RIP. Plot $\mathbf{B}$ represents a spectrum from a peak eluting off a column, showing both the RIP and PIP.

consideration for a future MCA includes the miniature ion trap [62] and quadrupole array instruments [13-16]. The main advantage of the miniaturized MCA, beside the obvious savings in resources, is the ability to place one of these instruments in each module, providing redundancy and more accurate in situ readings. These applications are not mentioned further here, as the focus of this discussion is on the more challenging analysis of trace levels of VOCs in cabin air samples.

The limited escape options and longer duration missions for ISS have prompted the development of the Volatile Organic Analyzer (VOA) for in situ monitoring of VOCs. The VOA's role is twofold: (1) routinely monitor the atmosphere for slow accumulation of a contaminant to a level of concern, (2) monitor the effectiveness of decontamination efforts following a contingency such as leaks from a payload experiment or spacecraft system. The most important task for the VOA is to provide data to the crew and ground personnel that verifies that the air quality has returned to nominal conditions following a contingency event.

Initially, GC/MS appeared to be the most promising technology for the VOA based on its analytical capabilities and its past use and wide acceptance for sensitive and reliable detection of trace levels of VOCs in air. Although several GC/MS instruments were considered including those based on ion trap detectors, a modified version of the commercial Viking GC/MS instrument was identified as the prime candidate. However, the rapid progress in the development of IMS and its growing application to battlefield detection of chemical and biological agents, and monitoring for explosives in airports [63] led to the consideration of GC/IMS as an alternate option. The key advantage of GC/IMS compared to GC/MS is that no vacuum system is required. This implies significant reductions in space, weight, power, and cost which, in conjunction with the technique meeting the performance requirements, eventually led to the selection of GC/IMS as the basis for a VOA for ISS. A thorough review of the advantages and disadvantages of both technologies for this application is provided elsewhere [64].

An illustration of how GC/IMS is used for monitoring VOCs in air is provided in Figure 13. Effluent from the GC column enters the ${ }^{63} \mathrm{Ni}$ source in the IMS, where ions are generated from the sample and resident gases at atmospheric pressure. Unless the chemistry is intentionally altered [65], the main reservoirs of charge are $\mathrm{H}_{3} \mathrm{O}^{+}$in positive ion mode and $\mathrm{O}_{2}^{-}$in negative ion mode. As analytes emerge from the GC column, they are ionized by charge exchange rather than direct ionization. The ions are propelled by a weak electric field down a tube against a countercurrent flow of a drift gas (typically nitrogen) to the collector. The resulting IMS spectrum plots the detected ion current as a function of time. The shape and size of an ion determines the amount of time it requires to reach the detector. Larger, less compact molecules have longer drift times and vice versa. A typical IMS spectrum is shown in Figure 14, in which the main reservoir of charge and analyte ions are referred to as the reactant ion peak (RIP) and product ion peak (PIP), respectively. An example of a chromatogram showing the elution of spe-

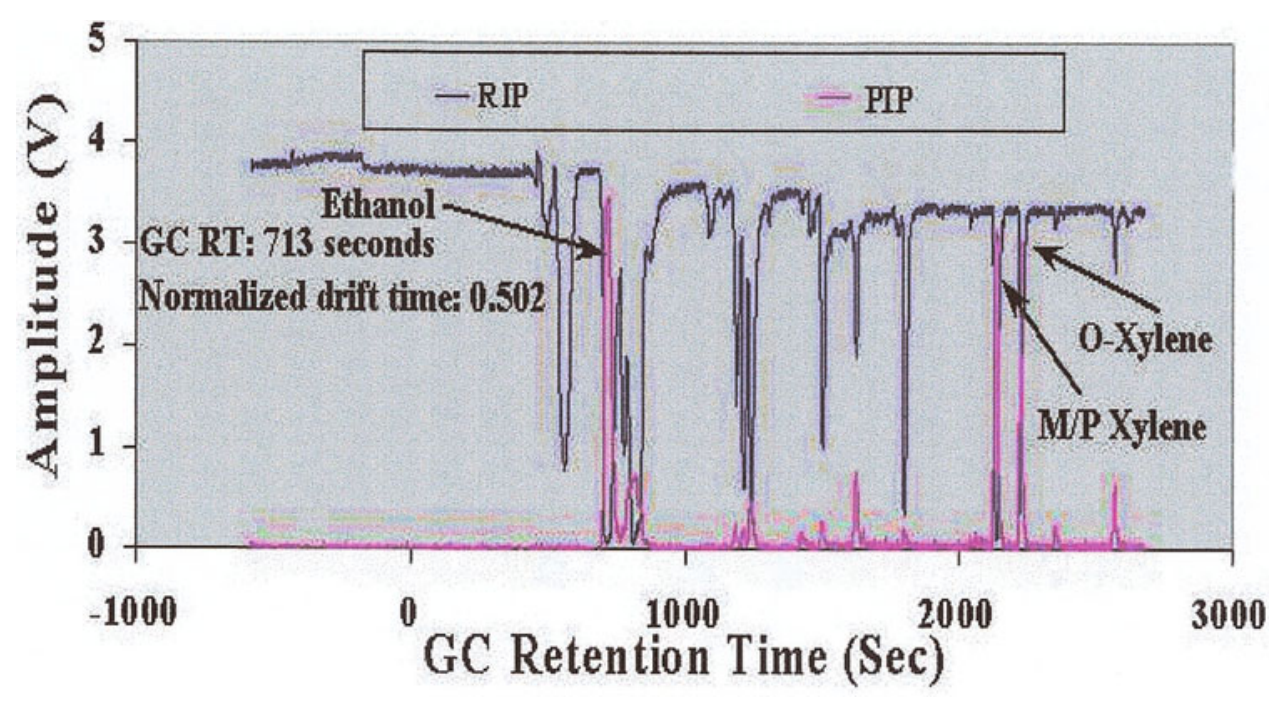

Figure 15. GC/IMS chromatogram of a mixture, showing plots of both the RIP and PIP versus time. 


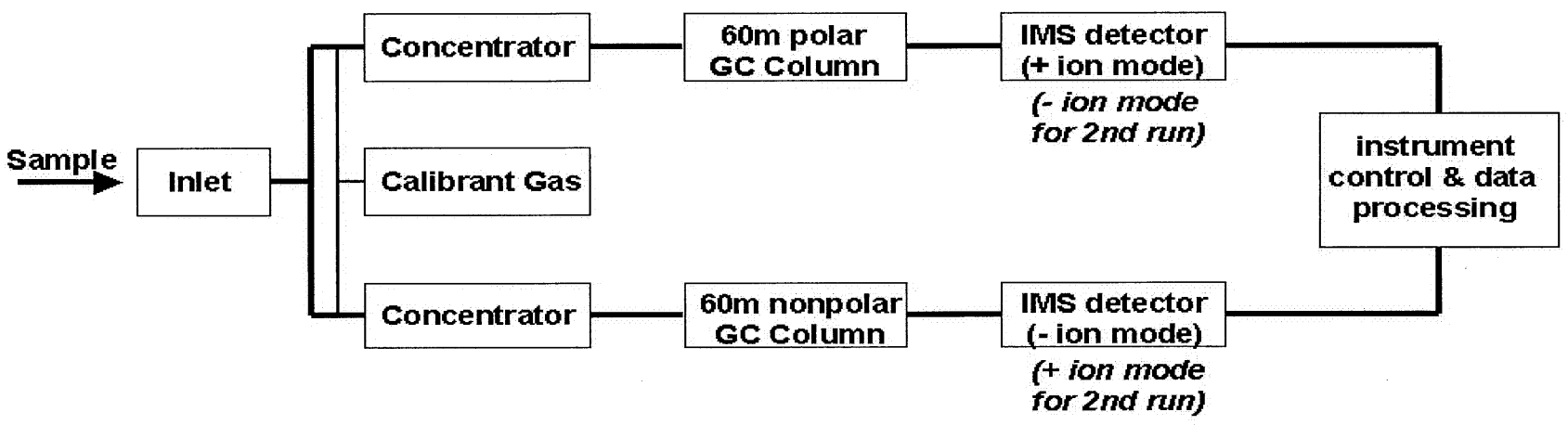

Figure 16. Schematic of VOA based on GC/IMS technology for monitoring both nonpolar and polar VOCs on ISS.

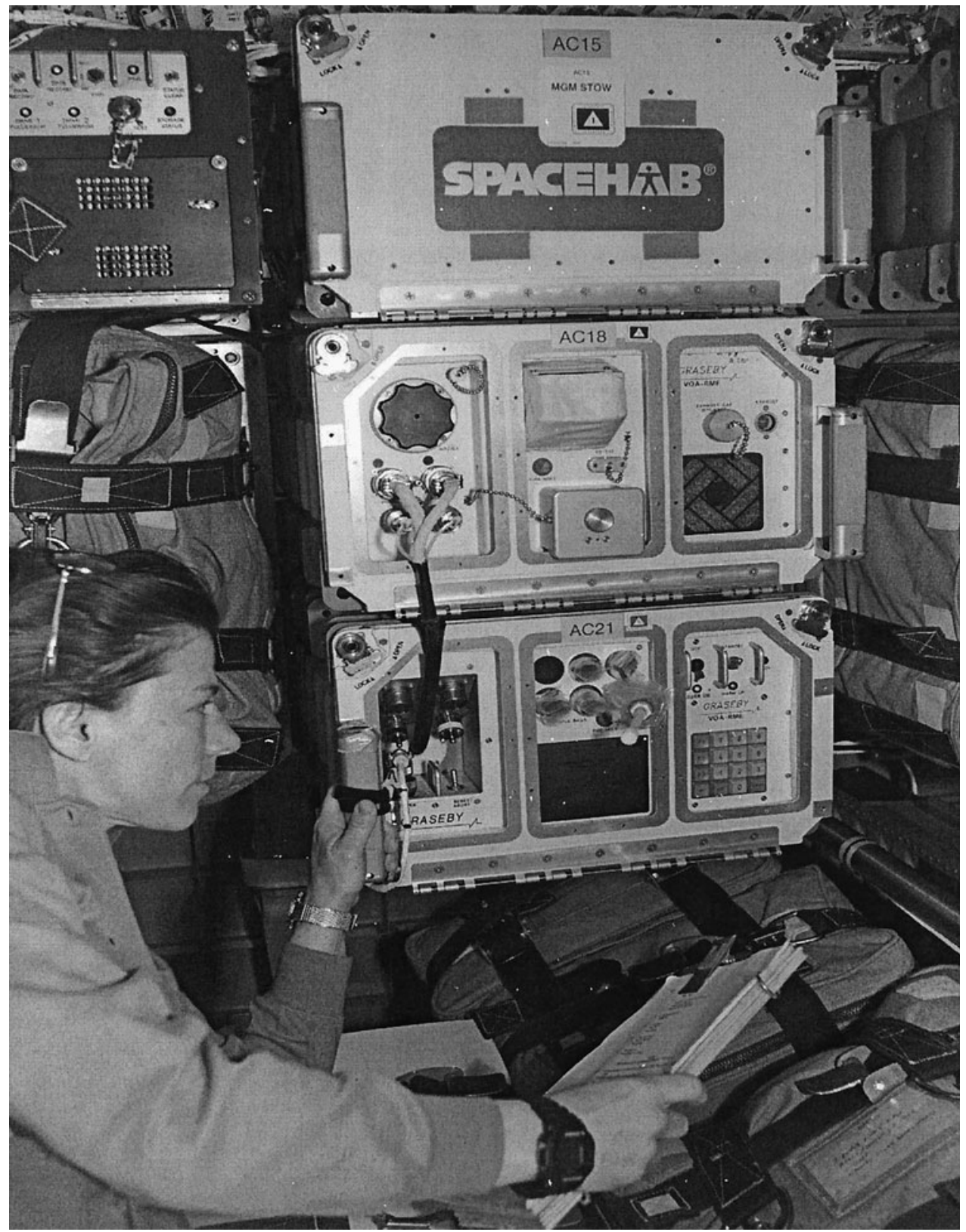

Figure 17. Photograph of the VOA-RME instrumentation flown on the Shuttle. 


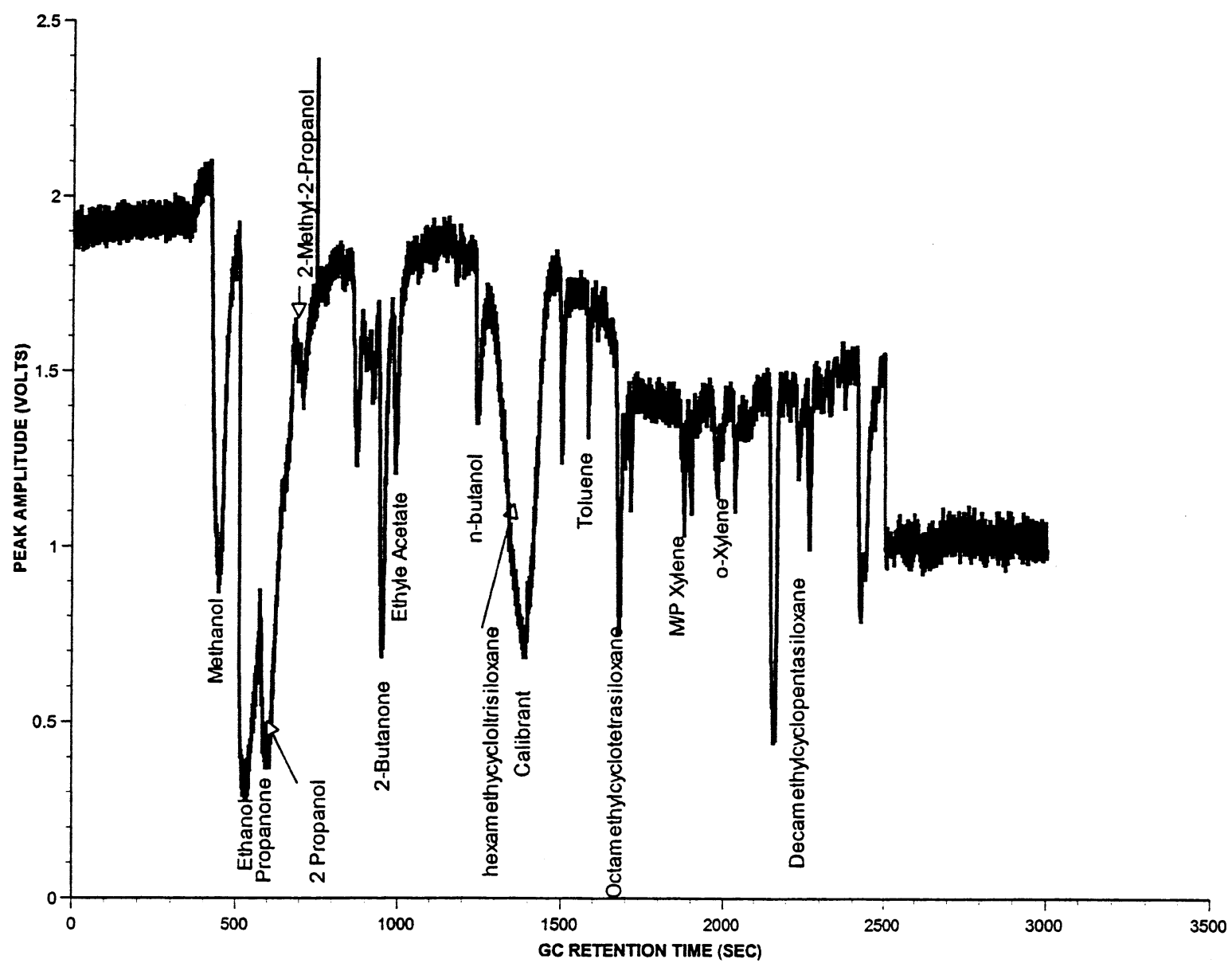

Figure 18. Results from a GC/IMS analysis of VOCs on Shuttle mission STS-89 performed as part of the VOA-RME.

cies off a GC column and subsequent detection by the IMS is shown in Figure 15 (in a plot that is analogous to a total ion chromatogram plot from a GC/MS analysis). Compounds are positively identified by GC retention times and normalized IMS ion drift times, both of which have been demonstrated to be highly reproducible [66]. Quantitation is achieved using the PIP response.

This new technology represented a major departure from past practice for monitoring VOCs in cabin atmospheres, and major effort was needed to render this technology suitable for space applications. NASA spearheaded the development of GC/IMS for cabin air quality monitoring, which involved collaborations between investigators in industry, academia, and NASA centers. A block diagram of the VOA components eventually developed for ISS are shown in Figure 16. This instrument, manufactured by Graseby (Watford, UK) and designed for redundancy, includes an inlet, two multisorbent-bed contaminant concentrators, two GC columns, two IMS detectors, and a computer for hardware control and data processing. The instrument and its operation is described in more detail elsewhere $[67,68]$.

A prototype VOA risk mitigation experiment (VOA-
RME) was flown on the Shuttle to evaluate the operation of the components in a microgravity environment [66]. A photograph of this instrument mounted in a rack on the Shuttle is shown in Figure 17. An example of results from analysis of an air sample acquired on orbit during this mission is presented in Figure 18. This plots the change in the RIP versus retention time, and shows the detection of aromatic hydrocarbons (toluene, $x y-$ lenes), polar VOCs (methanol, ethanol, propanone), and siloxanes (hexamethylcyclotrisiloxane, octamethylcyclotetrasiloxane). Although the VOA-RME experiment was not calibrated for siloxanes, these compounds were verified to be present in the Shuttle based on post-flight analyses of siloxane standards and archival samples on the same instrument.

A photograph of the VOA in a rack intended for eventual deployment on ISS is shown in Figure 19. This instrument has been developed and calibrated to monitor approximately 20 VOCs that are routinely detected in space environments. One might note that some compounds on the original list of 30 target VOCs are not on this shorter list. This is due to the fact that not all of the 30 compounds are readily amenable to GC or the two specific column types used in the VOA for separa- 


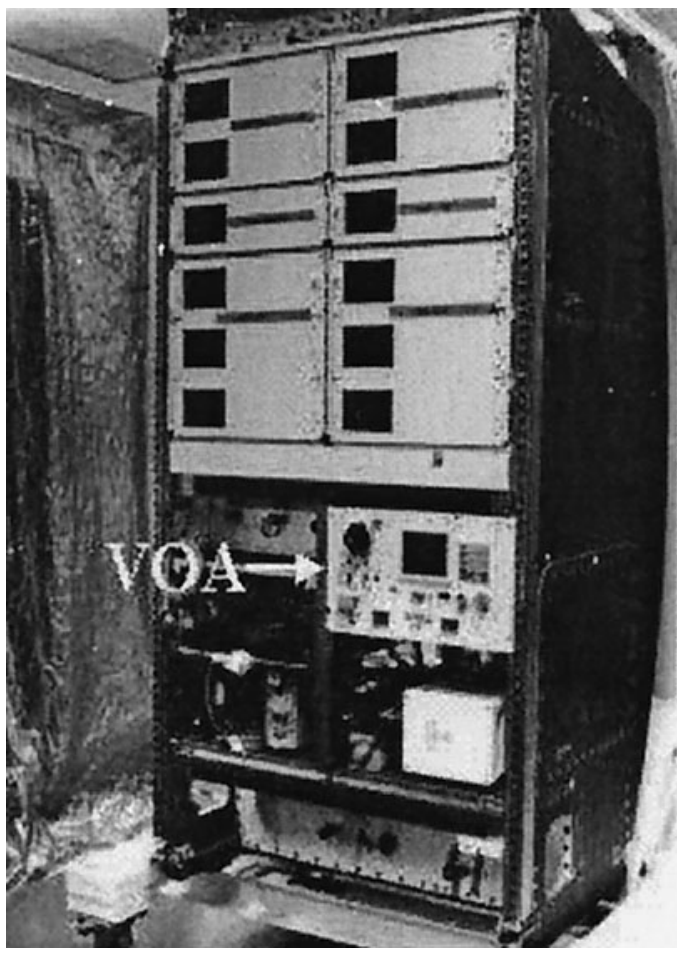

Figure 19. Photograph of the VOA mounted onto a rack for eventual deployment on ISS

tion of polar and nonpolar species. The VOA has been certified for flight and is being prepared for operation on ISS beginning in the summer of 2001. The target compounds and their corresponding calibration ranges are shown in Table 5. Initially, the VOA will perform VOC analyses once per day. Once the air composition on ISS reaches a steady state (approximately one year), the frequency of VOA analyses may be reduced to one to two times per week. The VOA's intended use will involve routine and contingency analyses for two years, with accuracies of $\pm 50 \%$ and precisions of $\pm 20 \%$.

Although GC/MS is still seen as a potentially powerful tool for monitoring VOCs, GC/IMS is now viewed as a more attractive technology primarily due to its lack of a vacuum system, better reliability, and ability to operate in severely degraded environments. Its simplicity, re- dundancy, and flexibility offer clear advantages compared to GC/MS. A significant limitation of the GC/IMS technology is not its sensitivity but a rather limited dynamic range, (generally less than two orders of magnitude), although this deficiency can be addressed through sampling variable amounts of air. One additional shortcoming is that when a true unknown is encountered, IMS spectra provide very limited information as to its true identity.

\section{Future Missions, and Emerging Technologies}

The wealth of knowledge developed over years from studies of cabin atmospheres, coupled with a clear need for routine monitoring to support long-term human presence in space has resulted in the development of an ambitious plan to implement multiple strategies for monitoring trace contaminants on ISS. This includes the use of GSC and SSAS devices to provide archival samples for subsequent ground-based analyses, kits to monitor formaldehyde, and the use of several specific analyzers to monitor combustion products and hydrazines [69]. It also includes for the first time the use of an instrument to perform in-situ analysis of VOCs-a GC/IMS instrument.

With longer duration space missions such as a lunar base still in the planning stages, the requirements for future instruments will become even more demanding. A search has already started for a second-generation VOA, which is much smaller, less complex, and more portable than the present VOA, but has equivalent or even improved analytical performance. The technologies currently under consideration for use in the later operational phases of ISS include FTIR, MS, and GC/ IMS [70]. Perhaps the two most important areas for progress are further reductions in size and the development of more powerful software for instrument control, data analysis, and self-optimization and diagnosis. Clearly, the instruments used for life support monitoring must be capable of autonomous operation and its user interface must allow varying levels of control.

Further into the future, as NASA looks to establish human presence on Mars, resources will drive the search toward micro and nanotechnologies. Already

Table 5. VOA target compounds and expected concentration ranges for ISS.

\begin{tabular}{lclc}
\hline Compound & $\begin{array}{c}\text { Calibration } \\
\text { Range }\left(\mathrm{mg} / \mathrm{m}^{3}\right)\end{array}$ & \multicolumn{1}{c}{ Compound } & $\begin{array}{r}\text { Calibration } \\
\text { Range }\left(\mathrm{mg} / \mathrm{m}^{3}\right)\end{array}$ \\
\hline \hline Methanol & $0.1-1.5$ & Ethanol & $0.2-3.5$ \\
i-Butanol & $0.3-4.0$ & 2-Methyl-2-propanol & $0.1-2.0$ \\
Ethanal & $0.1-1.2$ & Benzene & $0.1-1.5$ \\
m- and p-Xylenes & $0.4-5.0$ & Freon 22 & $0.3-5.0$ \\
o-Xylene & $0.2-2.7$ & 1,1,1-Trichloroethane & $0.1-1.6$ \\
Toluene & $0.2-2.6$ & Freon 113 & $0.2-2.5$ \\
Dichloromethane & $0.1-1.2$ & Hexane & $0.2-2.4$ \\
Acetone & $0.1-1.2$ & Pentane & $1.0-12$ \\
2-Butanone & $0.1-1.5$ & 2-Methyl-1,3-butadiene & $0.4-5.0$ \\
Ethyl acetate & $0.2-2.4$ & Trifluorobromomethane & $0.1-2.2$ \\
i-Propanol & $0.2-3.2$ & & \\
\hline
\end{tabular}




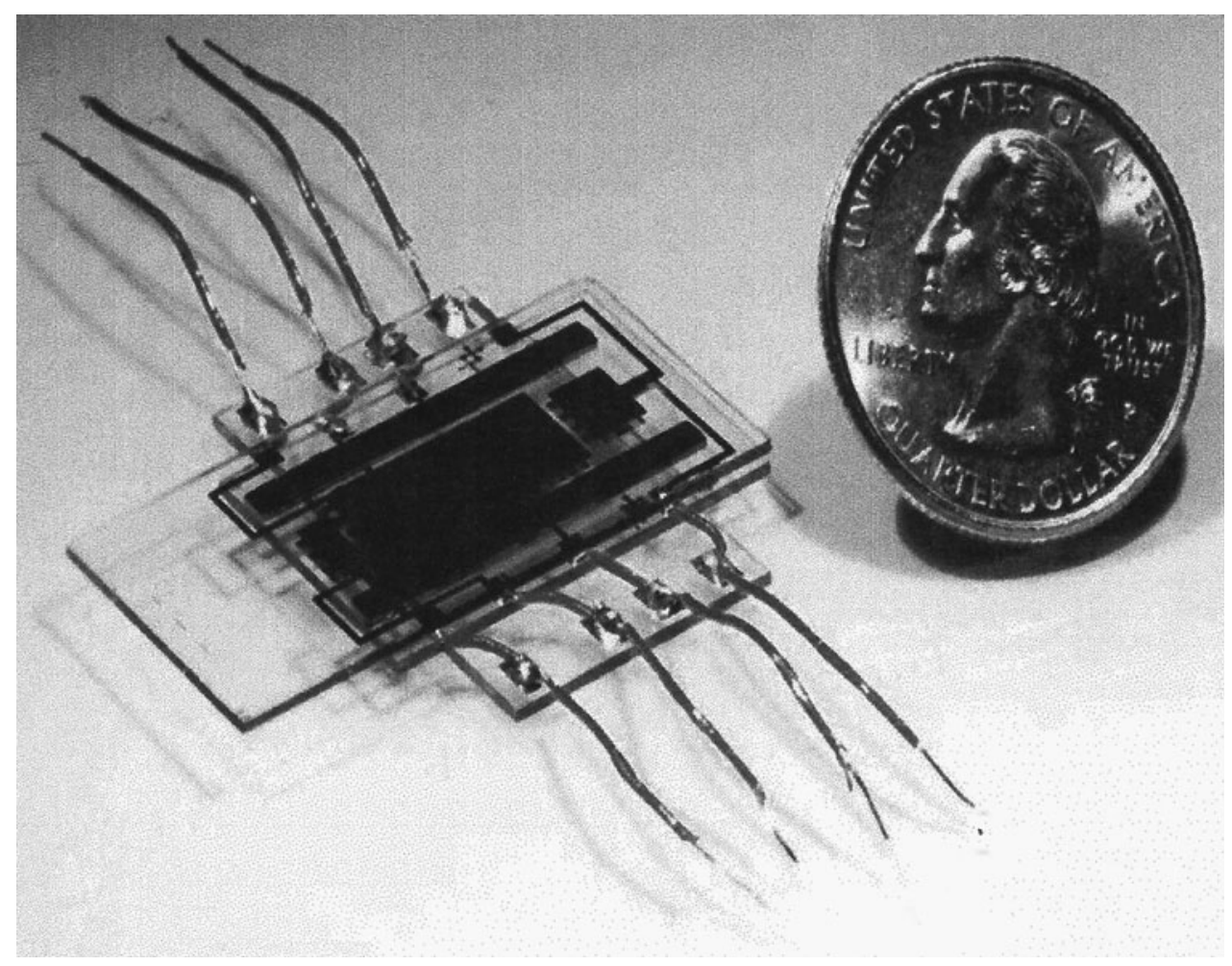

Figure 20. Photograph of a prototype, highly miniaturized IMS instrument.

hand-held [71] and chip-sized IMS detectors (Figure 20) are being developed. The lead times required to develop a functional, flight-qualified, miniaturized versions of these instruments are still long [72]. In the meantime, it is possible that further reductions in the size of MS instruments and in particular their vacuum systems might make MS a viable technology for future manned space missions.

\section{Conclusions}

The MS instruments that have been deployed for space applications are truly unique, with specifications and performance characteristics that are amazing even by today's standards. Not surprisingly, their development costs are very high, and a significant amount of time is required to certify and manifest equipment for flight experiments. These reasons, plus the ever-present uncertainty in funding levels and funding priorities, account for the limited number of commercial instrument manufacturers who have been involved in the development of MS instruments for space and remote applications.

Over the past few decades, two different approaches have led to successful MS instruments for space missions. Until recently, the use of MS instruments used for the analysis of planetary atmospheres has focused on continual evolution of proven designs rather than the adoption of radically new technologies. This is logical as the operating characteristics of MS render it well suited for operation in the vacuum of space. However, the use of MS for monitoring cabin atmospheres has recently undergone a major change, from the use of archival sampling and a posteriori analyses to the development of new technologies for in situ analyses. New types of mass spectrometers and new technologies have been developed and tested for analyzing trace contaminants in the unique environment of a spacecraft. Early attempts at developing a VOA capable of analyzing trace contaminants relied upon the proven approach of adapting planetary MS instruments. Competing technologies based on DSITMS, GC/MS, and GC/IMS were evaluated and compared. GC/IMS technology was chosen from these other technologies, and a VOA based on this technique is scheduled to begin operation on ISS in the summer of 2001.

As NASA looks forward to robotic probes and human missions in the next few decades, the requirements for analyses for both types of missions become more similar. Therefore, development efforts have already begun with the objective of serving both planetary probes and manned space missions. Micro-machined instruments have opened the door for consideration of ion traps, quadrupoles, sector instruments, and many other types of mass analyzers. New approaches such as IMS technology will continue to be developed and assessed for future missions. Furthermore, NASA has initiated programs in conjunction with academic and commercial sectors to develop technology to help reduce development costs. The goal of these various programs is to provide NASA with the equipment needed for space missions and to transfer the resulting technology to the commercial sector 
for terrestrial applications. It is likely that this approach will result in technologies that will revolutionize how air quality monitoring is performed on both space and Earthbased applications.

\section{Acknowledgments}

PTP would like to thank dedicated NASA civil servants and contractors who have collaborated with him on space applications of MS, including Carla Wong and Warren Belisle (NASA Ames Research Center), Bill Knott, Barbara Peterson, and Tim Griffin (Kennedy Space Center), and John James and Tom Limero (Johnson Space Center). Palmer acknowledges prior support from Amtech-8801, NASA Office of Advanced Technology, and NASA. The authors also thank the reviewers for their helpful comments and JASMS Associate Editor Veronica Bierbaum for allowing them the extra time needed to complete this manuscript.

\section{References}

1. Henry, C. M. Anal. Chem. 1999, 71, 264A-268A.

2. Workman, J.; Veltkamp, D. J.; Doherty, S.; Anderson, B. B.; Creasy, K. E.; Koch, M.; Tatera, J. F.; Robinson, A. L.; Bond, L.; Burgess, L. W.; Bokerman, G. N.; Ullman, A. H.; Darsey, G. P. Moyayen, F.; Bamberger, J. A. Greenwood, M. S. Anal. Chem. 1999, 71, 121R.

3. Badman, E. R.; Cooks, R. G. J. Mass Spectrom. 2000, 35, $659-671$.

4. Niemann, H. B.; Kasprzak, W. T. Adv. Space Res. 1983, 2, 261-270.

5. Mahaffy, P. Mass Spectrometers Developed for Planetary Missions. In Laboratory Astrophysics and Space Research, Ehrenfreund, P., Ed.; Kluwer Academic Publishing: 1999; 355-376.

6. White, F. A.; Wood, G. M. Mass Spectrometry Applications in Science and Engineering; Wiley: New York, 1986; pp 526-549.

7. Limero, T. F. Use of Mass Spectrometry Aboard United States Spacecraft. In Frontiers in Analytical Spectroscopy, Andrew, D. L.; Davies, A. M. Ed.; Royal Society of Chemistry: Cambridge, UK, 1995.

8. White, A. J.; Balmire, M. G.; Corlett, C. A.; Griffiths, B. W.; Martin, D. M.; Spencer, S. B.; Mullock, S. J. Rev. Sci. Instrum. 1998, 69, 565-571.

9. Syage, J. A.; Hanold, K. A.; Hanning-Lee, M. A. Proceedings of the 48th ASMS Conference on Mass Spectrometry and Allied Topics, 2000; 1252-1253.

10. Sinha, M. P.; Gutnikov, G. Anal. Chem. 1991, 63, 2012-2016.

11. Sinha, M. P.; Tomassian, A. D. Rev. Sci. Instrum. 1991, 62, 2618-2620.

12. Sinha, M. P.; Langstaff, D. P.; Narayan, D. J.; Birkinshaw, K. Int. J. Mass Spectrom. Ion Proc. 1998, 116, 99-102.

13. Ferran, R. J.; Boumsellek. S. J. Vac. Sci. Technol. A. 1996, 14, $1258-1265$.

14. Orient, O. J.; Chutjian, A.; Garkanian, G. Rev. Sci. Instrum. 1997, 68, 1393-1397.

15. Orient, O. J.; Chutjian, A.; Garkanian, V. Miniature, High Resolution, Quadrupole Mass Spectrometer Array: Applications to Environmental Monitoring and Control. SAE Technical Paper Series 972491; SAE: Warrendale, PA, 1997.

16. Chutjian, A.; Darrach, M. R.; Garkanian, V.; Jackson, S. P.; Molsberry, T. D.; Orient, O. J.; Karmon, D.; Holland, P. M.; Aalami, D. A Miniature Quadrupole Mass Spectrometer Array and GC for Space Flight: Astronaut EVA and Cabin Air Monitoring. SAE Technical Paper Series 2000-01-2300; SAE: Warrendale, PA, 2000.

17. Kaiser, R. E.; Cooks, R. G.; Stafford, G. C.; Syka, J. E. P.;
Hemberger, P. H. Int. J. Mass Spectrom. Ion Proc. 1991, 106, 79-115.

18. Badman, E. R.; Johnson, R.; Plass, W. R.; Cooks, R. G. Anal. Chem. 1998, 70, 4896-4901.

19. Kornienko, O; Reilly, P. T. A.; Whitten, W. B., Ramsey, J. M. Rapid Commun. Mass Spectrom. 1999, 13, 50-53.

20. Kornienko, O; Reilly, P.; Whitten, W.B.; Ramsey, J. M. Rev. Sci. Instrum. 1999, 70, 3907-3909.

21. Michel, E.; Rummel, J.; Sawin, C.; Buderer, M.; Lem, J. Results of the Skylab Medical Experiment M171-Metabolic Activity. In Johnston, R.; Dietlein, L. Ed., Biomedical Results of Skylab (NASA SP 377) NASA: Washington, DC, 1977.

22. Michel, E.; Rummel, J.; Sawin, C. Acta Astronautica 1975, 2, 351-365.

23. West, J. B.; Elliot, A. R.; Guy, H. J.; Prisk, G. K. J. Am. Med. Assoc. 1997, 227, 1957-1961.

24. Gas Analyzer System for Metabolic Analysis Physiology: Statement of Work. NASA Johnson Space Center: Houston, TX, unpublished report.

25. Griffin, T.; Naylor, G.; Hritz, R.; Barrett, C. Proceedings of the 45th ASMS Conference on Mass Spectrometry and Allied Topics; Santa Fe, NM, 1997; p 471.

26. Griffin, T.; Naylor, G.; Hritz, R.; Lampkin, C.; Mizell, C.; Adams, F.; Davis, B. A Multiple Detector Sample Delivery System for Remote Gas Monitoring (NASA NT) 2000, NASA: Washington, DC.

27. Helium Leak Detector with Improved Sample Delivery System. NASA Tech. Briefs; Washington, DC, Nov. 2000, 46-47.

28. Brasseaux, S. F.; Graf, J. C.; Lewis, J. F.; Meyers, K. E.; Rosenbaum, M. L.; Supra, L. N. Performance of the Physicochemical Air Revitalization System During the Lunar-Mars Life Support Test Project Phase III Test. SAE Technical Paper Series 981703 SAE : Warrendale, PA, 1998.

29. Farrow, P.; Kyranos, J.; Ralbovsky, P; Valentine, J. Proceedings of the 39th ASMS Conference on Mass Spectrometry and Allied Topics; Santa Fe, NM, 1991; pp 675-676.

30. Glaser, P. E.; Koger, G.; Larson, D. N.; Valentine, J. R.; Brooks, J. H.; Copeland, A. C.; Frost, R. L. Development of a Portable Contamination Detector for Use During EVA. SAE Trans. J. Aerospace, 1991, 100-1, 949-958.

31. Fimmel, R. O.; Colin, L.; Burgess, E. Pioneer Venus. NASA SP-461 NASA: Washington, DC, 1983; pp 21-26, 62-67.

32. Spencer, N.W. Proceedings of the Outer Planet Probe Technology Workshop, NASA Goddard Space Flight Center, Greenbelt, MD, 1975, pp 16-28.

33. Hoffman, J.H. Proceedings of the Outer Planet Probe Technology Workshop. NASA Goddard Space Flight Center, Greenbelt, MD, 1975, pp 29-44.

34. Anderson, D. M.; Biemann, K.; Orgel, L. E.; Oro, J.; Owen, T. Shulman, G. P. Toulmin, P.; Urey, H. C. Icarus 1972, 16, 111-138.

35. Biemann, K. Origins of Life 1974, 5, 417-430.

36. Biemann, K.; Oro, J.; Toulmin, P.; Orgel, L.E.; Nier, A. O.; Anderson, D. M.; Simmonds, P. G.; Flory, D.; Diaz, A. V.; Rushneck, D. R.; Biller, J. E.; Lafleur, A. L. J. Geophys. Res. 1977, 82, 4641-4658.

37. James, J. T.; Limero, T. F.; Leano, H. J.; Boyd, J. F.; Covington, P. A. Aviat. Space Environ. Med. 1994, 65, 851-857.

38. Palmer, P. T.; Belisle, W. Analysis of Volatile Organic Compounds on Mir Space Station-Final Report San Francisco State University: San Francisco, CA, 2000; pp 1-74.

39. Limero, T. F., personal communication.

40. Oyama, V.; Berdahl, B. J. Geophys. Res. 1977, 82, 4669.

41. Niemann, H. B. J. Geophys. Res. 1998, 103, 22831-22845.

42. Raulin, F. Adv. Space Res. 1999, 23, 61-66.

43. McEntire, R.; Managadze, G.; Rosenbauer, H.; Cheng, A. F.; Benson, R. C. Acta Astronautica 1996, 38, 377-384. 
44. Brinckerhoff, W. B.; Cornish, T. J.; McEntire, R. W.; Cheng, A. F.; Green, W. J. Miniature Time-of-Flight Mass Spectrometers for Planetary Exploration. 12th Sanibel Conference on Field Portable and Miniature Mass Spectrometry; Sanibel Island, FL, January, 2000.

45. Brinckerhoff, W. B.; Managadze, G. G.; McEntire, R. W.; Cheng, A. F.; Green, W. J. Rev. Sci. Instrum. 2000, 71, 536-545.

46. Wieland, P. O. Living in Space: The Design and Operation of the Life Support Systems on the International Space Station NASA/TM-1998-206956; NASA: Washington, DC, 1998, Volume I.

47. Wieland, P. O. Living in Space: The Design and Operation of the Life Support Systems on the International Space Station NASA/TM-1998-206956; NASA: Washington, DC, 1998, Volume II.

48. Cole, H; Ward, S.; Manuel S; Rather, D.; Simon, P.; Farant, J. P.; Krasnec, J.; Gouzenberg, A.; Moukhamedieva, L.; Mikos, K. SAE Trans. J. Aerospace 1998, 107-1, 885-899.

49. NSTS 1988 News Reference Manual, 1988, http://www.ksc.nasa.gov/shuttle/technology/sts-newsref/stsref-toc.html.

50. Liebich, H. M.; Bertsch, W.; Zlatkis, A.; Schneider, H. J. Aviat. Space Environ. Med. 1975, 46, 1002-1007.

51. Garcia, H. D.; Limero, T. F.; James, J. T. Setting Spacecraft Maximum Allowable Concentrations for 1 Hour or 24 Hour Contingency Exposures to Airborne Chemicals, SAE Trans. J. Aerospace 1992, 1517-1520.

52. James, J. T. Spacecraft Maximum Allowable Concentrations for Airborne Contaminants. JSC 20584; NASA Johnson Space Center, Houston, TX, February, 1995.

53. James, J. Toxicological Basis for Establishing Spacecraft Air Monitoring Requirements. SAE Trans. J. Aerospace 1998, 107-1, 854-859.

54. Limero, T.; James, J.; Cromer, R.; Beck, S. A Combustion Products Analyzer for Contingency Use During Thermodegradation Events on Spacecraft, SAE Trans. J. Aerospace 1991, 100-1, 1471-1480.

55. Palmer, P. T.; Karr, D.; Remigi, C. J. Field Anal. Chem. Tech. 2000, 4, 14-30.

56. Palmer, P. T.; Fan, X.; Remigi, C.; Nies, B.; Lee, L. Direct Sampling Ion Trap Mass Spectrometry-A Growing Toolkit for Air Quality Monitoring Applications. SAE Trans. J. Aerospace, 1998, 870-884.

57. Palmer, P. T.; Fan, X. Proceedings of the 47th ASMS Conference on Mass Spectrometry and Allied Topics; Dallas, TX, June, 1999; pp 1999-2000.
58. Wise, M.B. Proceedings of the 40th ASMS Conference on Mass Spectrometry and Allied Topics; Santa Fe, NM, 1992, p 1172.

59. Niu, W.; Rotheram, M.; Denckher, W.; Davidson, L. The Development of an Atmospheric Composition Monitor for the Environmental Control and Life Support System. SAE Technical Paper 921149; SAE: Warrendale, PA, 1992.

60. Lehotsky, R. B. Proceedings of the 21st Conference on Mass Spectrometry and Allied Topics; Santa Fe, NM, pp 403-405.

61. Torres, D.; Cole, A.; Hiss, J. Stand Alone Major Constituents Analyzer Flight Design SAE Technical Paper Series 941503; SAE: Warrendale, PA, 1994; pp 1-10.

62. T. Limero. Personal communication.

63. Eiceman, G.; Karpas, Z. Ion Mobility Spectrometry; CRC Press: Boca Raton, FL, 1994, pp 151-157.

64. Limero, T.; Cross, J.; Brittain, A.; Breach, J. Proceedings of the 5th International Workshop on Ion Mobility Spectrometry; Washington State University, Pullman, WA, 1996, p 411ff.

65. Eiceman, G.; Salazar, M.; Rodriquez, R; Limero, T.; Beck, T.; Cross, J.; James, J. Anal. Chem. 1993, 65, 1696-1702.

66. Limero, T.; Trowbridge, J.; Taraszewski, S.; Foster, J.; James, J. Results of the Risk Mitigation Experiment for the Volatile Organic Analyzer SAE Technical Paper Series 981745; SAE: Warrendale, PA, 1998.

67. Eiceman, G.; Karpas, Z. Ion Mobility Spectrometry; CRC Press: Boca Raton, FL, 1994; pp 165-188.

68. Limero, T.; Brokenshire, J.; Cumming, C.; Overton, E.; Carney, K.; Cross, J.; Eiceman, G.; James, J. A Volatile Organic Analyzer for Space Station: Description and Evaluation of a Gas Chromatography/Ion Mobility Spectrometer, SAE Trans. J. Aerospace 1992, 101-1, 1416-1424.

69. Trowbridge Jr., J. B.; Limero, T. F.; James, J. T. Strategy for Monitoring Trace Contaminants on International Space Station, SAE Trans. J. Aerospace 1998, 107-1, 866-869.

70. James, J. Expert Panel Review of Analytical Technologies Suitable for a Second-Generation Air Quality Instrument for the International Space Station JSC 28254; NASA Johnson Space Center: Houston, TX, Feb. 1998, pp 1-34.

71. Snyder, A. P.; Harden, C. S.; Brittain, A. H.; Kim, M. G.; Arnold, N. S.; Meuzelaar, H. L. C. Portable Hand-Held Gas Chromatography/Ion Mobility Spectrometry Device. Anal. Chem. 1993, 65, 299-306.

72. Taylor, S.; Srigengan, B.; Gibson, J.; Tindall, D.; Syms, R.; Tate, T.; Ahmad, M. Miniature Mass Spectrometer for Chemical and Biological Sensing, Proceedings of SPIE-International Society for Optical Engineering, Bellingham, WA, 2000; pp 187-193. 